\title{
Near-Zero Emissions Oxy-Combustion Flue Gas Purification
}

\section{Task 3: SOx/NOx/Hg Removal for Low Sulfur Coal}

\section{Final Topical Report}

January 1, 2009 to March 31, 2012

Prepared by Praxair, Inc.

Principal Authors

Monica Zanfir

Rahul Solunke

Minish Shah

September 2012

DOE Award No. DE-NT0005341

\section{Recipient}

Praxair, Inc.

175 East Park Drive

Tonawanda, NY 14150

Project Director

Minish Shah

Tel: (716) 879-2623

Email:minish_shah@praxair.com

Business Officer

Ray Drnevich

Tel: (716) 879-2595

Email: ray_drnevich@praxair.com 


\section{Disclaimer}

"This report was prepared as an account of work sponsored by an agency of the United States Government. Neither the United States Government nor any agency thereof, nor any of their employees, makes any warranty, express or implied, or assumes any legal liability or responsibility for the accuracy, completeness, or usefulness of any information, apparatus, product, or process disclosed, or represents that its use would not infringe privately owned rights. Reference herein to any specific commercial product, process, or service by trade name, trademark, manufacturer, or otherwise does not necessarily constitute or imply its endorsement, recommendation, or favoring by the United States Government or any agency thereof. The views and opinions of authors expressed herein do not necessarily state or reflect those of the United States Government or any agency thereof.” 


\section{Abstract}

The goal of this project was to develop a near-zero emissions flue gas purification technology for existing PC (pulverized coal) power plants that are retrofitted with oxycombustion technology. The objective of Task 3 of this project was to evaluate an alternative method of SOx, NOx and Hg removal from flue gas produced by burning low sulfur coal in oxy-combustion power plants. The goal of the program was to conduct an experimental investigation and to develop a novel process for simultaneously removal of SOx and NOx from power plants that would operate on low sulfur coal without the need for wet-FGD \& SCRs.

A novel purification process operating at high pressures and ambient temperatures was developed. Activated carbon's catalytic and adsorbent capabilities are used to oxidize the sulfur and nitrous oxides to $\mathrm{SO}_{3}$ and $\mathrm{NO}_{2}$ species, which are adsorbed on the activated carbon and removed from the gas phase. Activated carbon is regenerated by water wash followed by drying.

The development effort commenced with the screening of commercially available activated carbon materials for their capability to remove $\mathrm{SO}_{2}$. A bench-unit operating in batch mode was constructed to conduct an experimental investigation of simultaneous SOx and NOx removal from a simulated oxyfuel flue gas mixture. Optimal operating conditions and the capacity of the activated carbon to remove the contaminants were identified. The process was able to achieve simultaneous SOx and NOx removal in a single step. The removal efficiencies were $>99.9 \%$ for SOx and $>98 \%$ for NOx. In the longevity tests performed on a batch unit, the retention capacity could be maintained at high level over 20 cycles. This process was able to effectively remove up to $4000 \mathrm{ppm}$ SOx from the simulated feeds corresponding to oxyfuel flue gas from high sulfur coal plants.

A dual bed continuous unit with five times the capacity of the batch unit was constructed to test continuous operation and longevity. Full-automation was implemented to enable continuous operation (24/7) with minimum operator supervision. Continuous run was carried out for 40 days. Very high SOx (>99.9\%) and NOx (98\%) removal efficiencies were also achieved in a continuous unit. However, the retention capacity of carbon beds for SOx and NOx was decreased from 20 hours to 10 hours over a 40 day period of operation, which was in contrast to the results obtained in a batch unit. These contradictory results indicate the need for optimization of adsorption-regeneration cycle to maintain long term activity of activated carbon material at a higher level and thus minimize the capital cost of the system.

In summary, the activated carbon process exceeded performance targets for SOx and NOx removal efficiencies and it was found to be suitable for power plants burning both low and high sulfur coals. More efforts are needed to optimize the system performance. 


\section{Table of Contents}

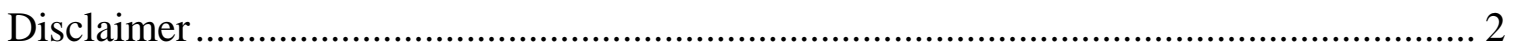

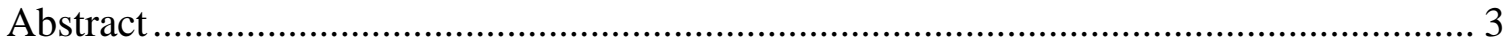

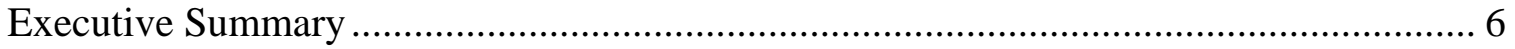

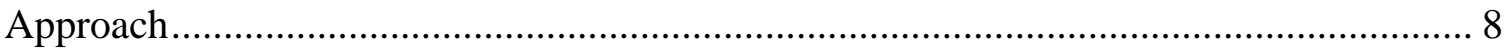

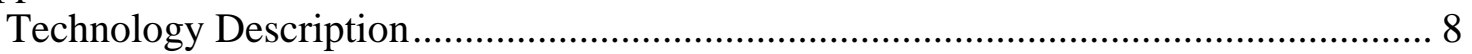

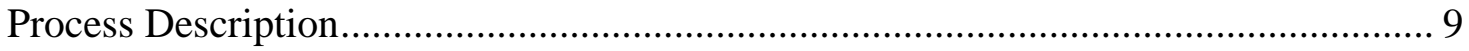

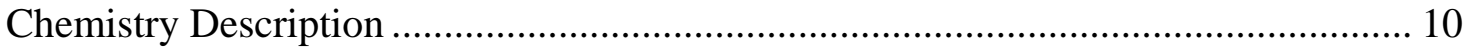

Subtask 3.1 - SOx and NOx Removal Material Selection ........................................... 11

Subtask 3.2 - Design and Construction of the Bench Unit.............................................. 13

Subtask 3.3 - SOx/NOx Removal Tests .................................................................... 15

Subtask 3.4 - Mercury and Residual NOx Removal Research ..................................... 16

Subtask 3.5 - Continuous Operation Unit .................................................................. 16

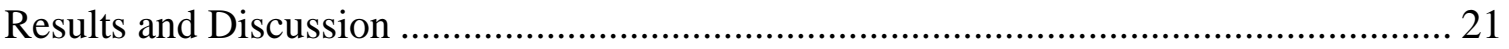

Subtask 3.1 - SOx and NOx Removal Material Selection .......................................... 21

Subtask 3.2 - Design and Construction of the Bench Unit.............................................. 21

Subtask 3.3 - SOx/NOx Removal Tests ..................................................................... 23

Subtask 3.4 - Mercury and Residual NOx Removal Research: ................................... 30

Subtask 3.5 - Continuous Operation Unit ................................................................... 30

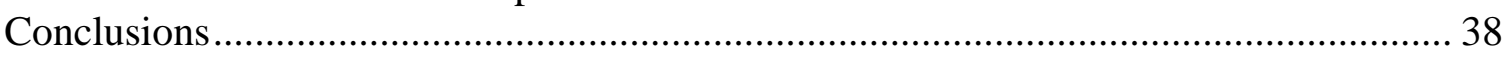

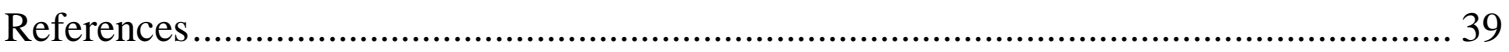

\section{List of Tables}

Table 1. Ranges for the Two Level Factorial Design for Selected Parameters ................. 15

Table 2. Dual Bed Activated Carbon Unit Cycle Steps..................................................... 20

Table 3. Activated Carbon Process - Bench Unit Results.................................................. 25

Table 4. Removal Efficiency for Bed 801 over 40 Days of Continuous Operation .......... 35

\section{List of Figures}

Figure 1. Schematic of the Oxy-coal Boiler Island.......................................................... 8

Figure 2. A CPU with Activated Carbon Process for SOx/NOx Removal........................... 9

Figure 3. Task 3 Activated Carbon Process for SOx/NOx Removal................................ 10

Figure 4. PI\&D of the Experimental Set-up for Material Testing..................................... 12

Figure 5. P\&ID of the Bench Unit for Simultaneous SOx/NOx Removal ........................ 14

Figure 6. Dual Bed Reactor System for Simultaneous SOx/NOx Removal...................... 18

Figure 7. Workflow to Assess the Activated Carbon Material Longevity ......................... 19

Figure 8. Relative Retention of $\mathrm{SO}_{2}$ for Different Activated Carbon Samples ................. 21

Figure 9. Bench Unit for Batch Mode Operation .......................................................... 22

Figure 10. Gas Cabinet for Toxic Gas Cylinders Storage and PLC Box........................... 22

Figure 11. Schematic of $\mathrm{CO}_{2}$ humidifier ...................................................................... 23

Figure 12. Reactor Outlet $\mathrm{SO}_{2}$ and NOx Concentrations as a Function of Time .............. 24

Figure 13. Influence of Temperature on Relative Retention of SOx and NOx ................ 26

Figure 14. Influence of Operating Pressure on Relative Retention of SOx and NOx ...... 27 
Figure 15. Influence of Operating Pressure on SOx and NOx Removal Efficiencies...... 27

Figure 16. Influence of $\mathrm{NO} / \mathrm{SO}_{2}$ Molar Ratio in Feed on Relative Retention .................. 28

Figure 17. Influence of $\mathrm{NO} / \mathrm{SO}_{2}$ Molar Ratio in Feed on Removal Efficiency ................ 28

Figure 18. Influence of Total Feed Flowrate on Relative Retention .............................. 29

Figure 19. Dual Bed Continuous Operation Unit ........................................................ 31

Figure 20. Temperature Profiles During the Regeneration Stage ................................... 32

Figure 21. Depletion of Sulfate Ions in Waste Water with the Number of Washes ......... 33

Figure 22. Reactor Effluent Concentrations as a Function of Time ............................... 34

Figure 23. Breakthrough Time for Bed 801............................................................... 35

Figure 24. Reactor Effluent Concentration Profiles for 30th Adsorption Cycle .............. 36 


\section{Executive Summary}

The objectives of this project were to carry out an experimental program to 1) enable development and design of a near zero emissions oxy-combustion flue gas purification processes having a high $\mathrm{CO}_{2}$ recovery for power plants burning high and low sulfur coals and, 2) to perform commercial viability assessment on the proposed technology.

The purpose of the Task 3 program was to investigate an alternative method of SOx and NOx removal from flue gas produced by burning low sulfur coal in oxy-coal power plants. In a typical power plant SOx is removed by reaction with lime or limestone producing disposable gypsum using a wet or dry-FGD at atmospheric pressure. The lime/limestone reagent cost, gypsum disposal cost, parasitic power plant load and equipment capital costs can be substantial. NOx removal is typically achieved in an SCR which requires ammonia as reagent, and substantial capital investment. Instead of processing flue gas at low pressures, the proposed Task 3 process aims to process flue gas at high pressure within the oxy-coal $\mathrm{CO}_{2}$ processing unit (CPU).

The process developed relies on direct oxidation of both $\mathrm{SO}_{2}$ and $\mathrm{NO}$ using activated carbon. In the presence of oxygen at ambient temperature, activated carbon acts as catalyst for the oxidation of $\mathrm{SO}_{2}$ and $\mathrm{NO}$. The oxidation products, $\mathrm{SO}_{3}$ and $\mathrm{NO}_{2}$, remain adsorbed on the carbon surface. When the flue gas stream containing oxygen and contaminants are passed over an activated carbon bed, the effluent essentially free of SOx and NOx is obtained. After carbon bed is saturated with SOx and NOx, it is regenerated by washing with water, followed by drying. Water reacts with the $\mathrm{SO}_{3}$ and $\mathrm{NO}_{2}$ to form dilute solution of sulfuric and nitric acids. A drying step is required to remove the water adsorbed on the active sites in order to complete the regeneration stage. A multi-bed system comprising of at least two beds is required for continuous operation with one bed on adsorption and other on regeneration.

Task 3 was composed of 5 subtasks. In an initial stage, subtask 3.1 focused on screening of commercially available catalytic carbon materials. Material samples were obtained from six suppliers and tested for their performance of removing $\mathrm{SO}_{2}$ only from a simulated flue gas in a simplified experimental rig. A preferred activated carbon material was selected for further experimental investigation. Optimal design parameters for designing a bench-scale test unit were also defined in this stage.

The main activity of subtask 3.2 was to design and build a bench-scale unit with a capacity of $\sim 0.025$ tpd $\mathrm{CO}_{2}$. In Subtask 3.3, influence of various process parameters such as pressure, temperature, and feed composition (water vapor; $\mathrm{SO}_{2}$ and $\mathrm{NO}$ concentration) on process performance was investigated. A design of experiments approach was used. The results showed excellent simultaneous removal of SOx and NOx, with efficiency higher than $99.9 \%$ for SOx and up to $98 \%$ for NOx exceeding the program targets of $99 \%$ and $95 \%$, respectively. The $\mathrm{CO}_{2}$ purification and the activated carbon material capacity to simultaneously retain SOx and NOx are favorably influenced by lower temperatures (ambient), and higher pressures. It was shown that the presence of NO 
enhances $\mathrm{SO}_{2}$ removal. Water presence in the vapor phase has an interesting effect. It enhances SOx removal, most probably due to formation of $\mathrm{H}_{2} \mathrm{SO}_{4}$ on the surface of the activated carbon, but it has a disadvantageous effect on NOx retention. It was observed that as long as the water vapor concentration stays below the SOx concentration in the feed, the water is consumed and contributes to augment the process performance. Any excess water vapor negatively affects the NOx removal and reduces the retention capacity of the activated carbon for the contaminants.

Subtask 3.4 consisted of a paper study on commercial methods for mercury removal. Due to the nature of the process, mercury condenses in various stages of the $\mathrm{CO}_{2}$ purification, more specifically in the condensate obtained in the flue gas compression train. Due to the acidic nature of the waste water obtained during the regeneration stage of the activated carbon process, part of mercury is expected to dissolve in the waste water.

A new Subtask 3.5 was added in the project scope in the final year of the project due to encouraging results obtained earlier. This Subtask focused on testing the activated carbon process in a scaled-up two-bed continuous unit. The process was scaled up by $5 \mathrm{X}$ to $\sim 0.125$ tpd $\mathrm{CO}_{2}$ equivalent capacity. The continuous unit consisted of two fixed bed reactors with valve skid to ensure continuous feeding of simulated flue gas. Full automation was used to enable continuous operation with minimum operator supervision, in order to test the activated carbon longevity and its performance evolution with operating time. It was observed that during the course of 40 days of continuous testing (24/7) the breakthrough time gradually dropped down from $\sim 20$ hrs to $\sim 10 \mathrm{hrs}$. The drop was steep till $12^{\text {th }}$ cycle after which it was more gradual. However, the $\mathrm{SO}_{2}$ and $\mathrm{NO}$ removal efficiencies of $\sim 100 \%$ and $97-98 \%$ were maintained during the whole testing period. Reduction in the breakthrough time suggests that improvement on regeneration stage is needed.

As proposed, the potential advantages of the Task 3 process was the ability to simultaneously remove SOx and NOx impurities, with high efficiency, and eliminate or reduce the need for traditional flue gas purification technologies (FGD and SCR). The following major conclusions can be made: 1) Commercially available activated carbon materials are suitable for simultaneously SOx and NOx removal at elevated pressures and ambient temperatures; 2) Continuity and scalability of the process is achievable through a multi-bed reactor design and a sequential operating schedule; 3) Good purification performance can be achieved, more specifically the contaminant content in the stream exiting the purification stage is: $\mathrm{SOx}<10 \mathrm{ppm}$, NOx $<20 \mathrm{ppm}$. 


\section{Approach}

Task 3 was composed of 5 subtasks. In an initial stage, Task 3.1 focused on screening of commercially available catalytic carbon materials for their performance to remove $\mathrm{SO}_{2}$ from concentrated $\mathrm{CO}_{2}$ stream. A bench-unit was designed and built as scope of subtask T3.2. A comprehensive experimental investigation was carried out under subtask T3.3. A paper study for mercury removal was completed as part of subtask T3.4. The aim of subtask 3.5 followed the successful demonstration of excellent simultaneous SOx and NOx removal in previous tasks, and had as main objective designing, building, and operation of a dual bed continuous unit. The latter was used to assess the activated carbon longevity and its performance change over time.

The following paragraphs provide the detailed approach used for each subtasks. In addition, technology, process and chemistry are described as background information.

\section{Technology Description}

The purpose of Task 3 project was to investigate an alternative method of SOx and NOx removal from flue gas produced by burning low sulfur coal in oxy-coal power plants. The process applies to oxy-combustion flue gas which is to be further compressed and processed for $\mathrm{CO}_{2}$ capture and sequestration (CCS). Figure 1 shows a high level diagram of an oxy-combustion boiler for this application where two streams of recirculated flue gas are used to moderate boiler temperature. This Figure shows the primary 'air' being treated in an FGD due to material of construction issues in the coal pulverizing and conveying equipment. Secondary air is not required to be treated. Combustion energy is used to generate steam and a turbine is used for power generation. The flue gas produced from the boiler island is then treated in the $\mathrm{CO}_{2}$ processing unit (CPU) for $\mathrm{CO}_{2}$ compression and purification.

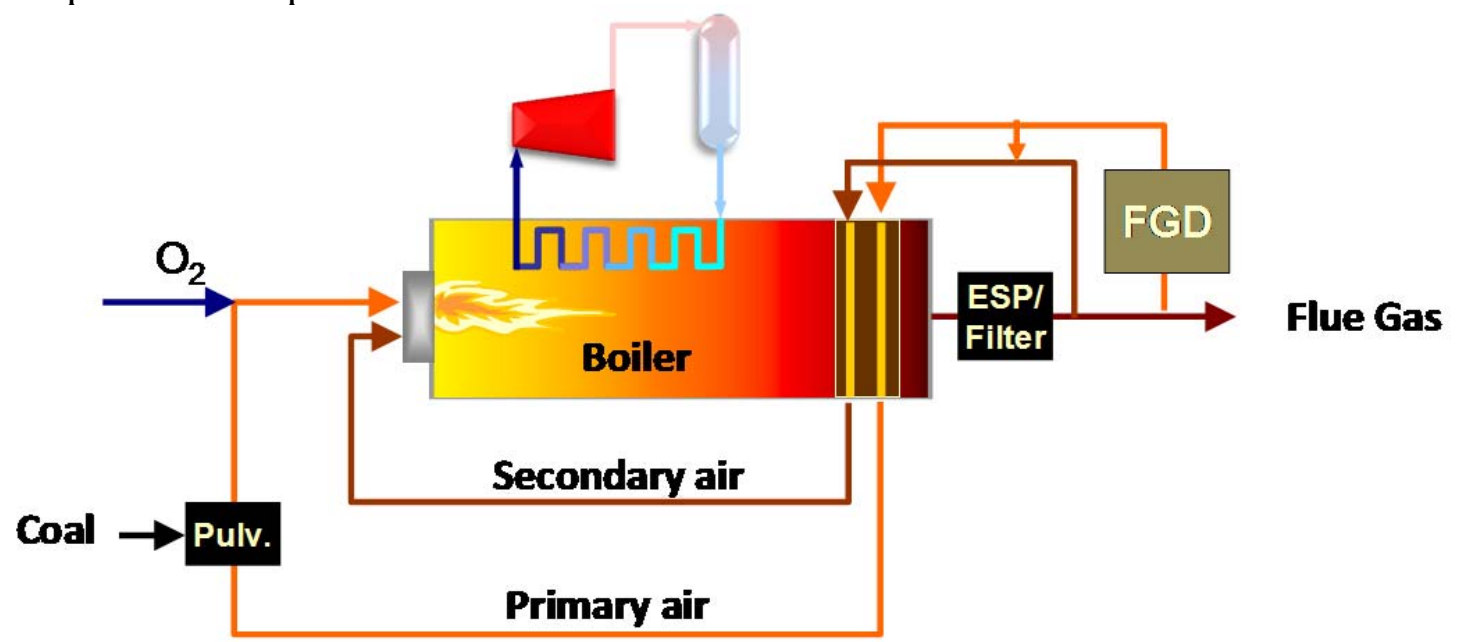

Figure 1. Schematic of the Oxy-coal Boiler Island

In a typical power plant SOx is removed by reaction with lime or limestone, producing disposable gypsum using a wet or dry-FGD at atmospheric pressure. The lime/limestone 
reagent cost, gypsum disposal cost, parasitic power plant load and equipment capital costs can be substantial. NOx removal is typically achieved in an SCR which requires substantial capital investment and also requires ammonia reagent.

The goal of this project was to develop a process, which simultaneously removes SOx and NOx within an oxy-coal CPU. Figure 2 shows a high level diagram of the entire CPU process. Raw flue gas from boiler is cooled and then compressed. Next the flue gas is treated in the proposed Task 3 process for SOx and NOx removal. Following the Task 3 process the flue gas is purified in a Cold Box cycle to concentrate the $\mathrm{CO}_{2}$. The purified $\mathrm{CO}_{2}$ is further compressed to the final product pressure. The 'Cold Box Vent' stream is processed in a vacuum pressure swing adsorption (VPSA) process to recover $\mathrm{CO}_{2}$ which is recycled to the raw gas compressor. The process vent gas, mostly composed of $\mathrm{O}_{2}, \mathrm{~N}_{2}$ and Ar is heated and expanded for power recovery.

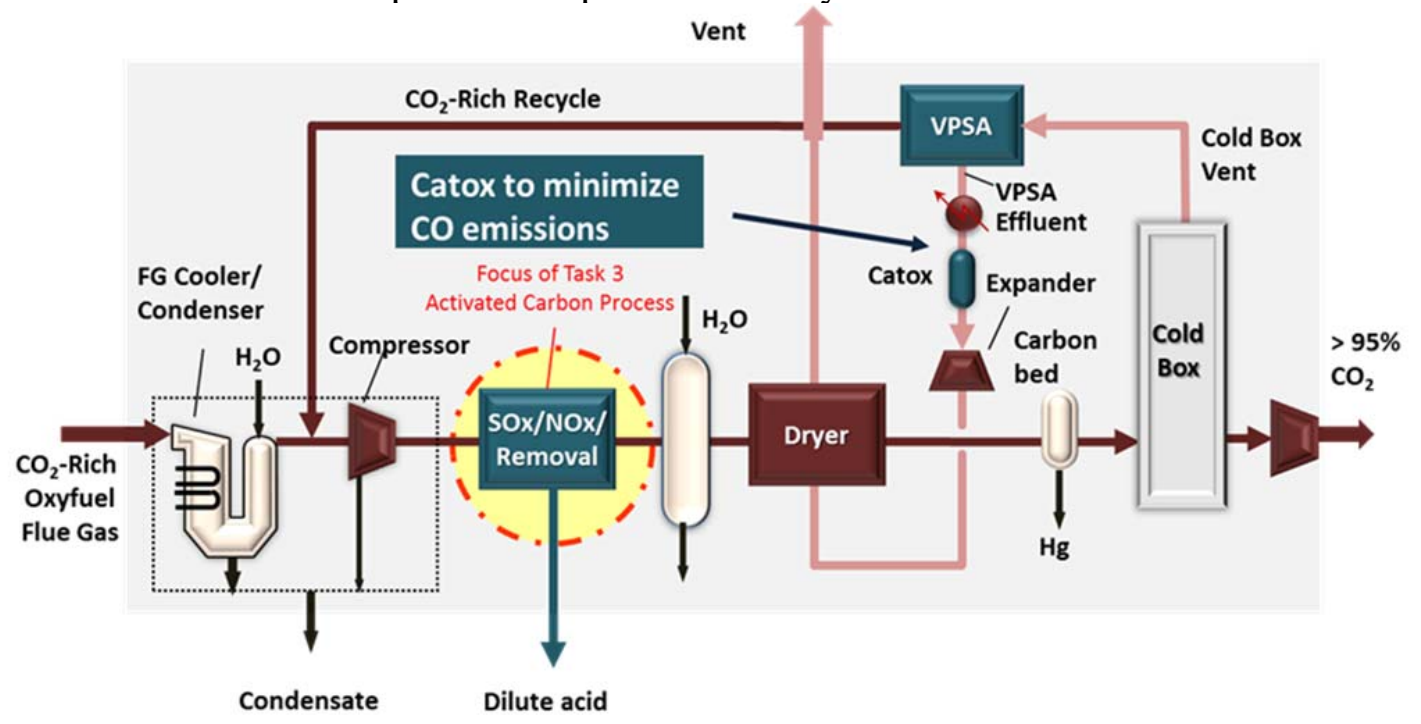

Figure 2. A CPU with Activated Carbon Process for SOx/NOx Removal

\section{Process Description}

Figure 3 below shows the configuration of the Task 3 process for flue gas purification by simultaneously removing SOx and NOx at high pressure. In order to ensure continuous operation, the process must consist of at least two activated carbon beds alternatively operated in adsorption and regeneration modes. Typically the flue gas containing SOx and NOx passes through the carbon bed from bottom to top. Once the carbon bed in service is almost saturated with contaminants a valve system switches the flue gas feed to the second bed, while regeneration starts for the saturated bed. Regeneration of the carbon material is achieved by passing a stream of water from top to bottom. The waste water can be recycled in order to minimize the waste water generated. A drying step is required to remove the water adsorbed on the active sites in order to complete the regeneration stage. The nitrogen can be used for drying. The Task 3- treated flue gas would be further processed in the $\mathrm{CPU}$ to produce purified $\mathrm{CO}_{2}$ stream. 


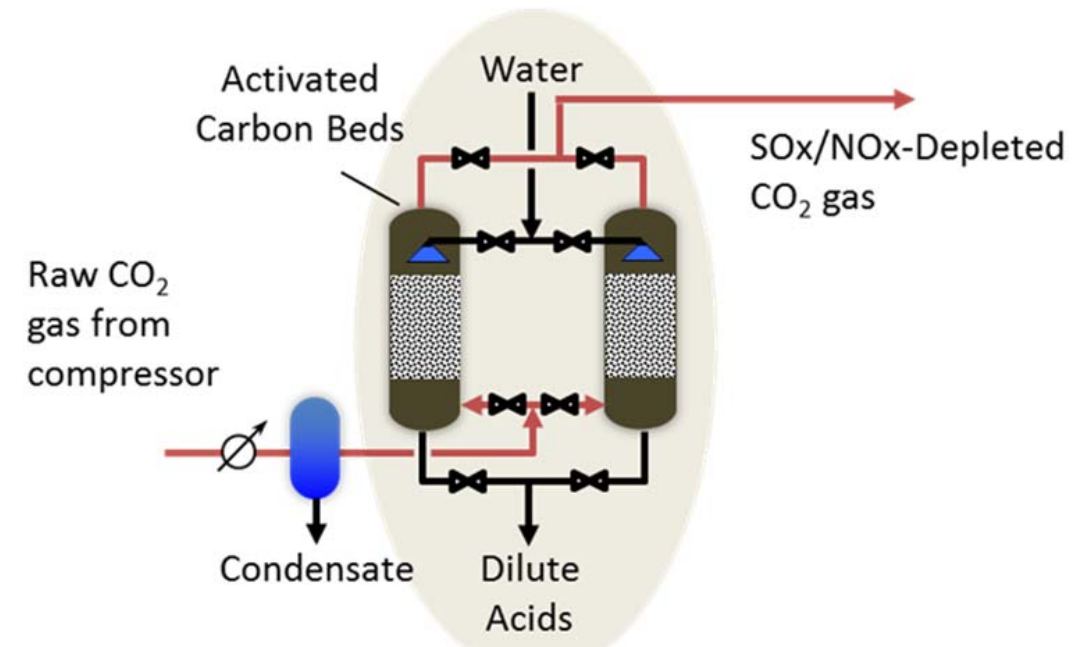

Figure 3. Task 3 Activated Carbon Process for SOx/NOx Removal

\section{Chemistry Description}

In the Task 3 process a number of heterogeneous and homogeneous reactions take place for NOx and SOx oxidation, and formation of the sulfuric and nitric acids. The elevated pressure which would be present in the CPU is another key feature which increases the rates of adsorption related reactions and mass transfer fluxes.

Adsorption stage involves homogeneous and catalytic oxidation of the contaminants and adsorption of the oxidation products on the activated carbon material. The inferior oxides of sulfur and nitrogen are oxidized to their superior oxides by oxygen through the flowing reactions:

$\mathrm{NO}+0.5 \mathrm{O}_{2} \rightarrow \mathrm{NO}_{2} \quad$ Reaction 1

$\mathrm{SO}_{2}+0.5 \mathrm{O}_{2} \rightarrow \mathrm{SO}_{3} \quad$ Reaction 2

Reaction 1 takes place homogeneously in the gas phase and is enhanced by high pressure and low temperature. Reaction 2 is heterogeneously catalyzed by the activated carbon. $\mathrm{NO}_{2}$ and $\mathrm{SO}_{3}$ are the species that are adsorbed on the carbon. Water presence in the vapor phase significantly affects the reaction mechanism for $\mathrm{SO}_{2}$ removal. One of the proposed mechanisms [1] for $\mathrm{SO}_{2}$ adsorption onto activated carbon in the presence of oxygen and water vapor is given below:

$\mathrm{SO}_{2} \rightarrow \mathrm{SO}_{2}$ (ad)

$\mathrm{H}_{2} \mathrm{O} \rightarrow \mathrm{H}_{2} \mathrm{O}(a d)$
Reaction 3

Reaction 4 


$$
\begin{aligned}
& 0.5 \mathrm{O}_{2} \rightarrow \mathrm{O}_{(a d)} \quad \text { Reaction } 5 \\
& \mathrm{SO}_{2(a d)}+\mathrm{O}_{(a d)} \rightarrow \mathrm{SO}_{3(a d)} \quad \text { Reaction } 6 \\
& \mathrm{SO}_{3 \text { (ad) }}+\mathrm{H}_{2} \mathrm{O}_{(\mathrm{ad})} \rightarrow \mathrm{H}_{2} \mathrm{SO}_{4}(\mathrm{ad}) \quad \text { Reaction } 7 \\
& \mathrm{H}_{2} \mathrm{SO}_{4}(\mathrm{ad}) \mathrm{n} \mathrm{H}_{2} \mathrm{O}_{(\mathrm{ad})} \rightarrow \mathrm{H}_{2} \mathrm{SO}_{4} \bullet n \mathrm{H}_{2} \mathrm{O}_{(a d)} \quad \text { Reaction } 8
\end{aligned}
$$

This mechanism suggests that once the $\mathrm{H}_{2} \mathrm{SO}_{4}$ is produced the active sites occupied by water and sulfur trioxide are freed and the activated carbon retention capacity increases. In addition the hydroscopic nature of the sulfuric acid makes possible to fix the water molecules from the gas stream. $\mathrm{NO}_{2}$ can react with $\mathrm{SO}_{2}$ in homogeneous phase and can act as a catalyst for oxidation of $\mathrm{SO}_{2}$.

$\mathrm{SO}_{2}+\mathrm{NO}_{2} \rightarrow \mathrm{SO}_{3}+\mathrm{NO} \quad$ Reaction 9

Reaction 9 indicates that the presence of $\mathrm{NO}_{2}$ enhances the oxidation of $\mathrm{SO}_{2}$. If $\mathrm{O}_{2}$ is present in excess, the NO formed in Reaction 9 can be easily re-oxidized.

Once the activated carbon is saturated, the SOx and NOx components breakthrough and their presence in reactor gas effluent can be detected. The adsorption capacity of the activated carbon can be restored by passing a water stream over the carbon bed. In this manner water reacts with $\mathrm{SO}_{3}$ and $\mathrm{NO}_{2}$ forming the corresponding acids.

$$
\begin{array}{ll}
\mathrm{SO}_{3}+\mathrm{H}_{2} \mathrm{O} \rightarrow \mathrm{H}_{2} \mathrm{SO}_{4} & \text { Reaction } 10 \\
3 \mathrm{NO}_{2}+\mathrm{H}_{2} \mathrm{O} \rightarrow 2 \mathrm{HNO}_{3}+\mathrm{NO} & \text { Reaction } 11
\end{array}
$$

The regeneration stage consists of washing the activated carbon bed with water followed by drying with an inert gas stream (i.e. $\mathrm{N}_{2}$ or $\mathrm{CO}_{2}$ ). Consequently, most of the sulfur oxides can be captured as sulfuric acid. However, due to the stoichiometry of Reaction 11, a third of the NOx adsorbed on the activated carbon are produced back as NO during the regeneration stage.

\section{Subtask 3.1 - SOx and NOx Removal Material Selection}

The subtask 3.1 addressed selection of adequate activated carbon materials. Material selection was based on testing commercially available materials for $\mathrm{SO}_{2}$ removal. Since $\mathrm{SO}_{2}$ is typically the contaminant with a higher concentration, performance of its removal was considered as a first requirement for a preliminary material performance screening.

The PI\&D of the experimental set-up for material screening is given in Figure 4. Each material was loaded as a fixed bed in a $3 / 4$ " tube with a length of 12 ”. A flow of process gas of 3 SLPM was passed over the fixed bed, ensuring at least 6 s residence time. The process gas source was obtained by blending a mixture of $2 \% \mathrm{SO}_{2}, 40 \% \mathrm{O}_{2}$ in $\mathrm{CO}_{2}$ from 
a gas cylinder, with pure $\mathrm{CO}_{2}$ delivered directly from a service tank. The typical composition of the process gas fed to the activated carbon bed was about $2000 \mathrm{ppm} \mathrm{SO}_{2}$, $4 \% \mathrm{O}_{2}$ in $\mathrm{CO}_{2}$. For tests to be performed at $80 \mathrm{C}(176 \mathrm{~F})$, the $3 / 4$ " tube was placed in a furnace, which was controlled based on the temperature measurement taken by a thermocouple inserted axially in the middle of the bed. The process gas pressure was maintained at about 15 bar (221 psia).

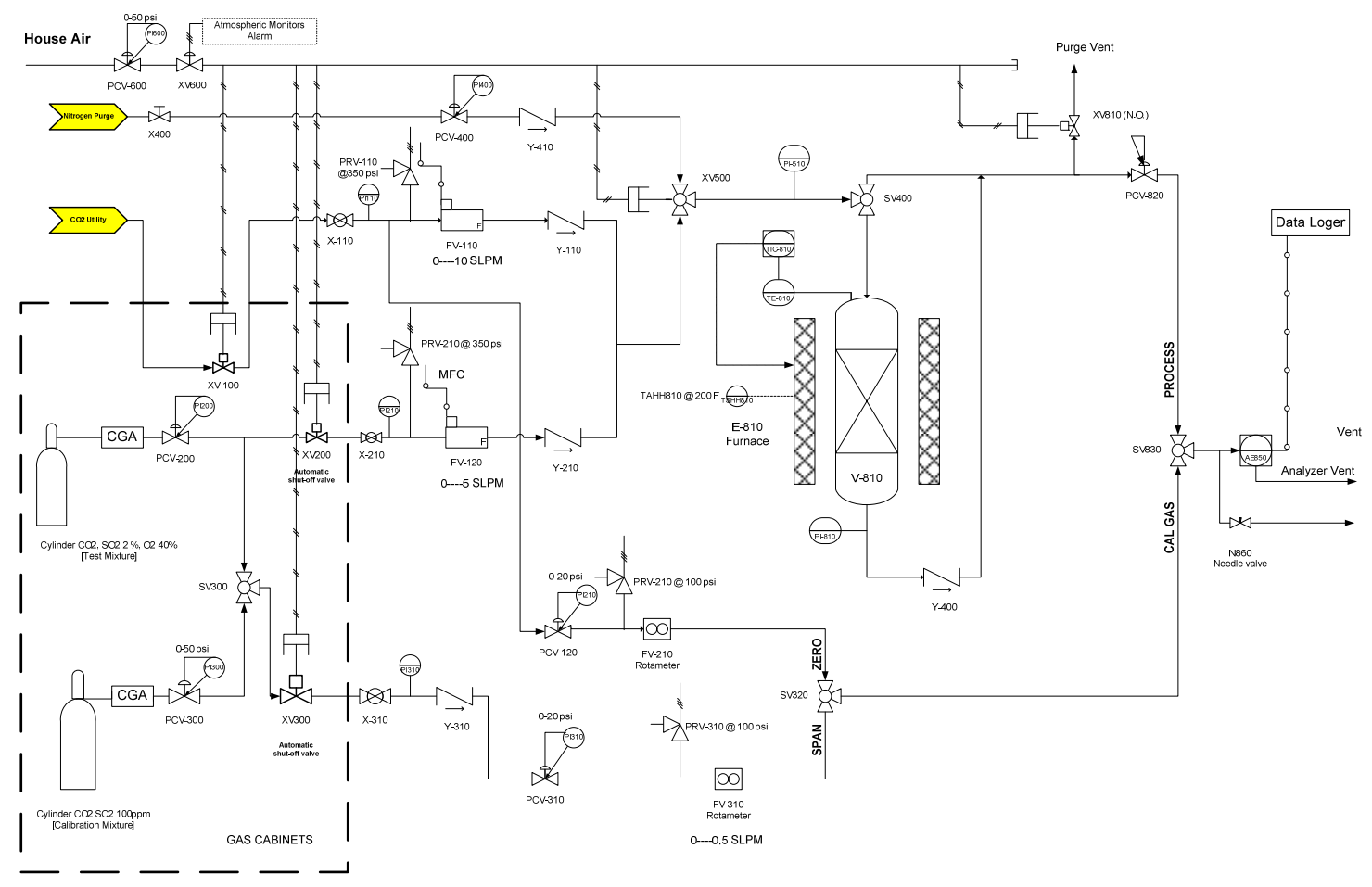

Figure 4. PI\&D of the Experimental Set-up for Material Testing.

The test procedure consisted of three consecutive steps. First, a break-through test for $\mathrm{SO}_{2}$ was carried out by passing the process gas containing $\mathrm{SO}_{2}$ over the activated carbon bed. The $\mathrm{SO}_{2}$ concentration was monitored continuously by means of a PG250 Horiba Analyzer. The test was completed when the $\mathrm{SO}_{2}$ concentration in the effluent stream reaches $100 \mathrm{ppm}$. In the second step, the bed saturated with $\mathrm{SO}_{2}$ was regenerated by water washing. In the last step, a small amount of inert gas, more specifically $\mathrm{N}_{2}$, was passed through the bed to remove free water. The materials were tested for at least three consecutive cycles. The performance index utilized to compare various activated carbon materials was calculated as the amount of $\mathrm{SO}_{2}$ removed per unit weight of carbon in the bed. Six different materials were tested. The material that had the capacity to retain the highest amount of $\mathrm{SO}_{2}$ was selected for further testing of simultaneous removal of $\mathrm{SOx}$ and NOx. 


\section{Subtask 3.2 - Design and Construction of the Bench Unit}

The scope of this subtask was to build a bench-scale unit operated in batch mode for a comprehensive experimental investigation of simultaneously SOx and NOx removal over a wide range of operating conditions and feed compositions. The PI\&D of the bench-unit is given in Figure 5. A fixed bed test reactor containing about $100 \mathrm{~g}$ of activated carbon, and a simulated flue gas flow of 10 SLPM were used. The test reactor had a diameter of 1 ”, while the length of the carbon bed was about 18”. The simulated gas flow mixtures flows from top to bottom. A high precision high pressure water pump was used to provide the amount of process water so that the feed composition achieved up to 1800 ppm of water vapors. On top of the activated carbon bed, 6" height of inert ceramic beads were used to ensure mixing of the process gas with process water, and water vaporization.

Typical flue gas composition used during the investigation was:

$$
\begin{aligned}
& \text { 85-90 \% (vol.) } \mathrm{CO}_{2} \\
& 4-6 \% \text { (vol.) } \mathrm{N}_{2} \\
& 2-6 \% \text { (vol.) } \mathrm{O}_{2} \\
& 200-750 \text { ppmv NO } \\
& 1000-3000 \text { ppmv } \mathrm{SO}_{2}
\end{aligned}
$$

The source of $\mathrm{SO}_{2}$ component was provided by gas cylinders of $6 \% \mathrm{SO}_{2}$ in $\mathrm{N}_{2}$, while the source for $\mathrm{NO}$ component was provided from $3 \% \mathrm{NO}$ in $\mathrm{N}_{2}$ gas cylinders. High purity $\mathrm{O}_{2}$ gas cylinders were used to deliver the required $\mathrm{O}_{2}$, while pure $\mathrm{CO}_{2}$ was delivered directly from a service tank. Mixtures with various compositions and humidity levels were prepared by adjusting the mass flow controllers used to deliver each gas stream and the high precision high pressure water metering pump for water delivery.

In order to maintain the test bed at constant temperature, up to $80 \mathrm{C}(176 \mathrm{~F})$, the 1 ” test reactor was placed in a heating blanket, which was controlled based on the temperature measurement taken by a thermocouple inserted axially in the middle of the activated carbon bed. The process gas pressure of up to 15 bar (221 psia) was maintained by means of a back-pressure regulator. The experimental-set up was provided with capabilities for regeneration by washing it with water, and drying with nitrogen. 


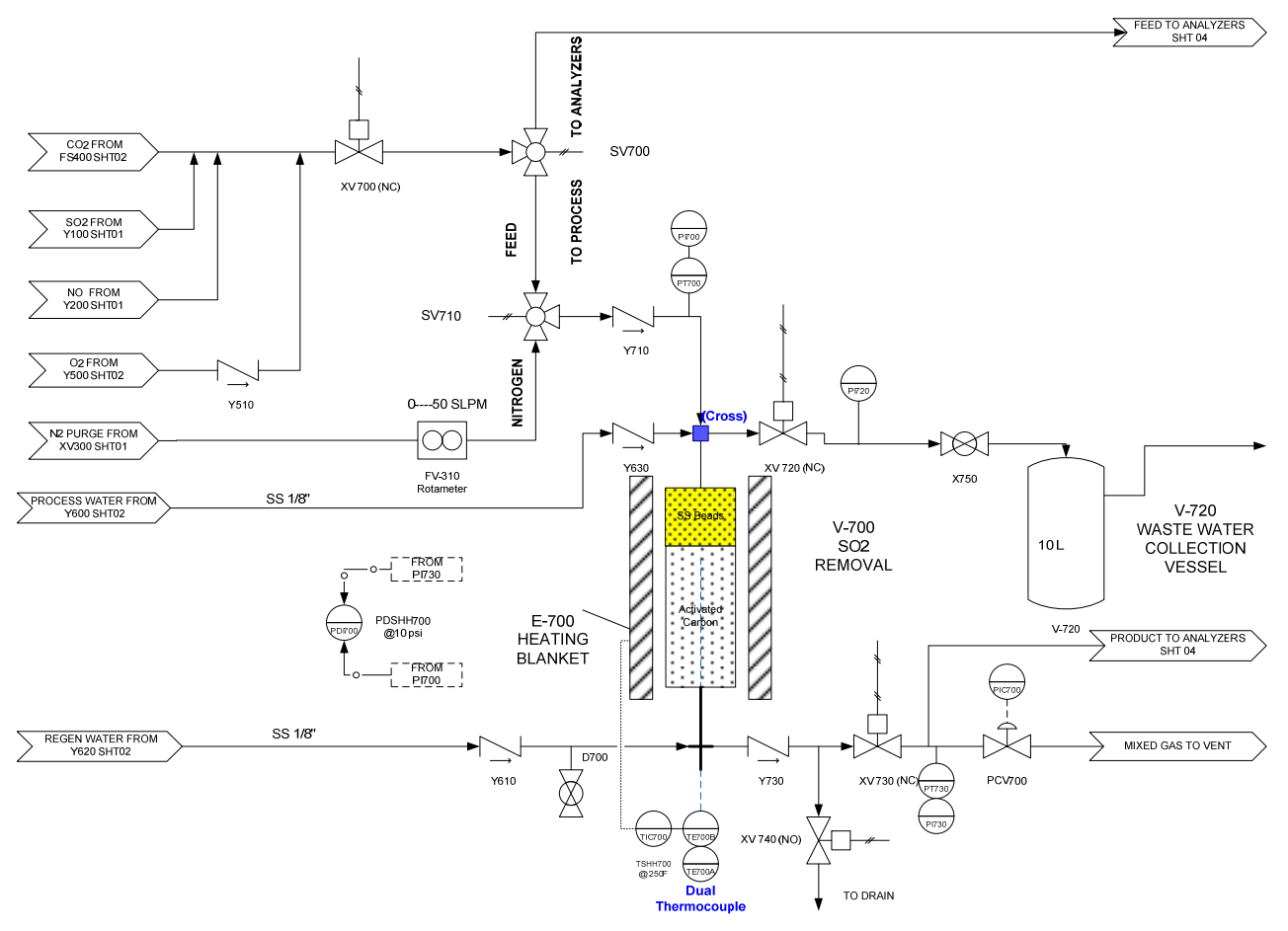

Figure 5. P\&ID of the Bench Unit for Simultaneous SOx/NOx Removal

The $\mathrm{SO}_{2}, \mathrm{NO}$, and $\mathrm{NO}_{2}$ concentrations of the gas stream exiting the test reactor were monitored continuously by the Emerson Analyzer. A sample conditioning system based on Nafion membrane was utilized to remove the water contained in the process gas stream before sending it to the analyzers.

A fairly high degree of automation was included to comply with safety requirements, to allow remote control, and acquire relevant experimental data. For this purpose a Programmable Logic Controller (PLC) and a user interface design in LabView was used. Due to high toxicity of the gaseous components involved, precautions were taken to ensure safety measures and protection of operators. The feed and calibration gases containing $\mathrm{SO}_{2}$ and $\mathrm{NO}$ were placed in a secured gas cabinet provided with appropriate vents. Continuous atmospheric monitors for the toxic components were installed. Any detection of the toxic gases initiated the automatic shut-down of the system. Automatic shut-off valves, for the feed gases and water used for process and regeneration, were provided in the system for this purpose. In case of emergency shut-down, a flow of nitrogen purged the entire system.

The bed was regenerated by flowing water from bottom to top such that the total volume of regeneration water flown was at least 6 times the carbon volume. The waste water was collected in a vessel, neutralized with sodium bicarbonate and discharged. Waste water samples were collected for selected experiments and analyzed for their content of the 
following ions: Sulfates $\left(\mathrm{SO}_{4}{ }^{2}\right)$, Nitrates $\left(\mathrm{NO}_{3}^{-}\right)$, Nitrite $\left(\mathrm{NO}_{2}^{-}\right)$. A Hach 890 colorimeter was used for this purpose.

\section{Subtask 3.3 - SOx/NOx Removal Tests}

An experimental plan was designed to investigate the influence of several key operating parameters on process efficiency and carbon capacity to retain the SOx and NOx. The investigated operating parameters were: temperature, pressure, inlet composition (NO / $\mathrm{SO}_{2}$ molar ratio), presence of water in the inlet flue gas stream, and total inlet flowrate (residence time). A two-level factorial design was employed to screen the impact of key process variables for simultaneous removal of SOx and NOx on activated carbon. The values for the high-low levels considered for each parameter are given in Table 1.

Table 1. Ranges for the Two Level Factorial Design for Selected Parameters

\begin{tabular}{|l|c|c|}
\hline Parameter & Low & High \\
\hline Temperature, C & 20 & 80 \\
\hline Pressure, bar & 3.4 & 15 \\
\hline Feed Humidification & No (Dry) & Yes (Saturation) \\
\hline Total Feed Gas Flow, SLPM & 10 & 25 \\
\hline $\mathrm{SO}_{2}$ Concentration, ppm & 2000 & 4000 \\
\hline NO Concentration, ppm & 0 & 750 \\
\hline
\end{tabular}

A total of 24 carbon beds were tested for selected conditions. For each bed the adsorption-regeneration cycle was repeated 3-5 times. During each breakthrough test the reactor gas effluent composition was continuously monitored. The breakthrough completion was considered at the time when either contaminant (SOx or NOx) achieved $30 \mathrm{ppm}$ in the reactor gas effluent. For the adsorption stage, the process performance was determined by calculating the amounts of contaminants retained on the activated carbon, as well as the efficiency of their removal from the gas stream. The retention of each contaminant is calculated as:

Retention $_{\mathrm{i}}=\frac{\left[\int_{0}^{\mathrm{BT}}\left(\mathrm{F}_{\mathrm{i}} \cdot y_{i}^{\text {in }}\right) d t-\int_{0}^{\mathrm{BT}}\left(\mathrm{F}_{\mathrm{T}} \cdot y_{i}^{\text {out }}\right) d t\right] \cdot \frac{1}{V_{0}}}{m_{\text {carbon }}}, \frac{\text { moles of } \mathrm{SO}_{2} \text { or NO}}{\text { g Carbon }}$

Where:

i $\quad \mathrm{NO}$, or $\mathrm{SO}_{2}$

$\mathrm{F}_{\mathrm{i}} \quad$ gas flow of fed contaminant from source, SLPM

$y^{\text {in }}{ }_{i} \quad$ molar fraction of contaminant $i$ from source

$\mathrm{F}_{\mathrm{T}}$ total gas flow rate at the reactor outlet, SLPM

$\mathrm{y}^{\text {out }}{ }_{\mathrm{i}}$ molar fraction of contaminant $\mathrm{i}$ at reactor outlet

t time, min

BT breakthrough time (to $30 \mathrm{ppm}$ of $\mathrm{SO}_{2}$ or $\mathrm{NO}$ ), min 
$\mathrm{V}_{0} \quad$ molar volume in standard conditions, $1 /$ mole

A cumulative molar retention can be calculated as:

$$
\text { Retention }_{\mathrm{SO}_{2}+\mathrm{NO}}=\text { Retention }_{\mathrm{SO}_{2}}+\text { Retention }_{\mathrm{NO}}
$$

The removal efficiency for each component is calculated as

$$
\text { Efficiency }_{\mathrm{i}}=\frac{\left[\int_{0}^{\mathrm{BT}}\left(\mathrm{F}_{\mathrm{i}} \cdot y_{i}^{\text {in }}\right) d t-\int_{0}^{\mathrm{BT}}\left(\mathrm{F}_{\mathrm{T}} \cdot y_{i}^{\text {out }}\right) d t\right]}{\int_{0}^{\mathrm{BT}}\left(\mathrm{F}_{\mathrm{i}} \cdot y_{i}^{\text {in }}\right) d t} \cdot 100
$$

\section{Subtask 3.4 - Mercury and Residual NOx Removal Research}

In any conventional coal fired power plant, mercury emission is an environmental issue, wherein current regulations in several countries require its removal down to less than 5$10 \mathrm{mg} / \mathrm{MWh}$. However, in any oxy-coal combustion power plant with $\mathrm{CO}_{2}$ capture, mercury is not only an environmental issue but also an operational issue specifically to any aluminum based heat exchangers (BAHX) used in the $\mathrm{CO}_{2}$ clean-up and processing unit. It may be expected that mercury should be removed down to $0.01 \mu \mathrm{g} / \mathrm{Nm}^{3}$ (this is the current standard applied in any NG/LNG plant) [2]. A literature survey was conducted to assess the current state of art for mercury removal options.

\section{Subtask 3.5 - Continuous Operation Unit}

A continuous unit was designed and built to address the scalability of the process, to prove continuous operation $24 \mathrm{~h} \times 7$ days per week, and to test the activated carbon material longevity.

The system was designed to fit in a walk-in hood. It was assembled on three removable skids: gases and water supply skid, reactor skid, and analytical skid. This modularity ensured easy access for maintenance and potential modifications. The supply skid contained the mass flow controllers for the source gases, the water pumps for process water and regeneration water, and a high pressure high precision pump for liquid $\mathrm{SO}_{2}$ delivery. The gas supply system delivered $\mathrm{CO}_{2}$, specialty gases and $\mathrm{N}_{2}$. The $\mathrm{CO}_{2}$ was delivered from a six-ton bulk tank located outside the building. $\mathrm{SO}_{2}$ source was either a 6 $\% \mathrm{SO}_{2}$ in $\mathrm{N}_{2}$ mixture delivered from a gas cylinders or liquid $\mathrm{SO}_{2}$. NO source was a $3 \%$ $\mathrm{NO}$ in $\mathrm{N}_{2}$ mixture delivered from a gas cylinder. The cylinders of toxic gases were placed in gas cabinets adjacent to the hood.

The P\&ID of the reactor skid is given in Figure 6. It consisted of two fixed bed reactors holding activated carbon. Each bed had a diameter of 2” and a length of 20". To ensure 
good flow distribution a segment of inert packing was placed above and below the carbon bed. The flue gas containing SOx and NOx passed through the carbon bed from bottom to top. Once the carbon bed in service was saturated with contaminants, a valve system switched the flue gas feed to the second bed; and regeneration started for the saturated bed. Regeneration of the carbon material was achieved by flooding the carbon beds with water from bottom to top. A pair of electronic level indicators was used to show the water level in the reactor vessel and signal when the water covered the height of the carbon bed. Once flooded, the reactor held the water for $10 \mathrm{~min}$, and then the water was drained at the bottom of the bed by slightly pressurizing the reactor with nitrogen. This flooding sequence was repeated at least 6 times to ensure removal of the sulfuric and nitric acid formed during the regeneration stage. After washing with water, the carbon bed was dried using nitrogen at $180{ }^{\circ} \mathrm{F}$. The dried bed was cooled by passing nitrogen at ambient temperature.

The simulated flue gas contained $450 \mathrm{ppm} \mathrm{SO}$, $200 \mathrm{ppm} \mathrm{NO}, 4 \% \mathrm{O}_{2}$, $94 \% \mathrm{CO}_{2}$, water vapor of about $1725 \mathrm{ppm}$ (saturation level), and $\mathrm{N}_{2}$ as balance. The gas flow was delivered at 250 psia and ambient temperature. The unit was designed for continuous operation. For this purpose full automation was implemented to meet safety standards and allow it to run unattended. The reactor outlet gas composition was continuously monitored using an MLT Rosemount/Emerson analyzer. During the regeneration stage, potential gases degassing from the carbon beds were redirected towards a second analyzer (Horiba PG-250) by using a secondary flow of carbon dioxide. This was done to quantify the amount of contaminants that were not captured in the liquid phase during the regeneration stage.

Adsorption/regeneration cycles were carried out $24 / 7$ for 40 days. The waste water was neutralized before discharging. Occasionally, the waste water was sampled and its content of $\mathrm{SO}_{4}{ }^{2-}, \mathrm{SO}_{3}{ }^{2-}, \mathrm{NO}_{3}{ }^{-}$, and $\mathrm{NO}^{-}$was analyzed in order to determine the amount of SOx and NOx converted to sulfuric and nitric acid. Standard colorimetric methods for waste water analysis were used. 


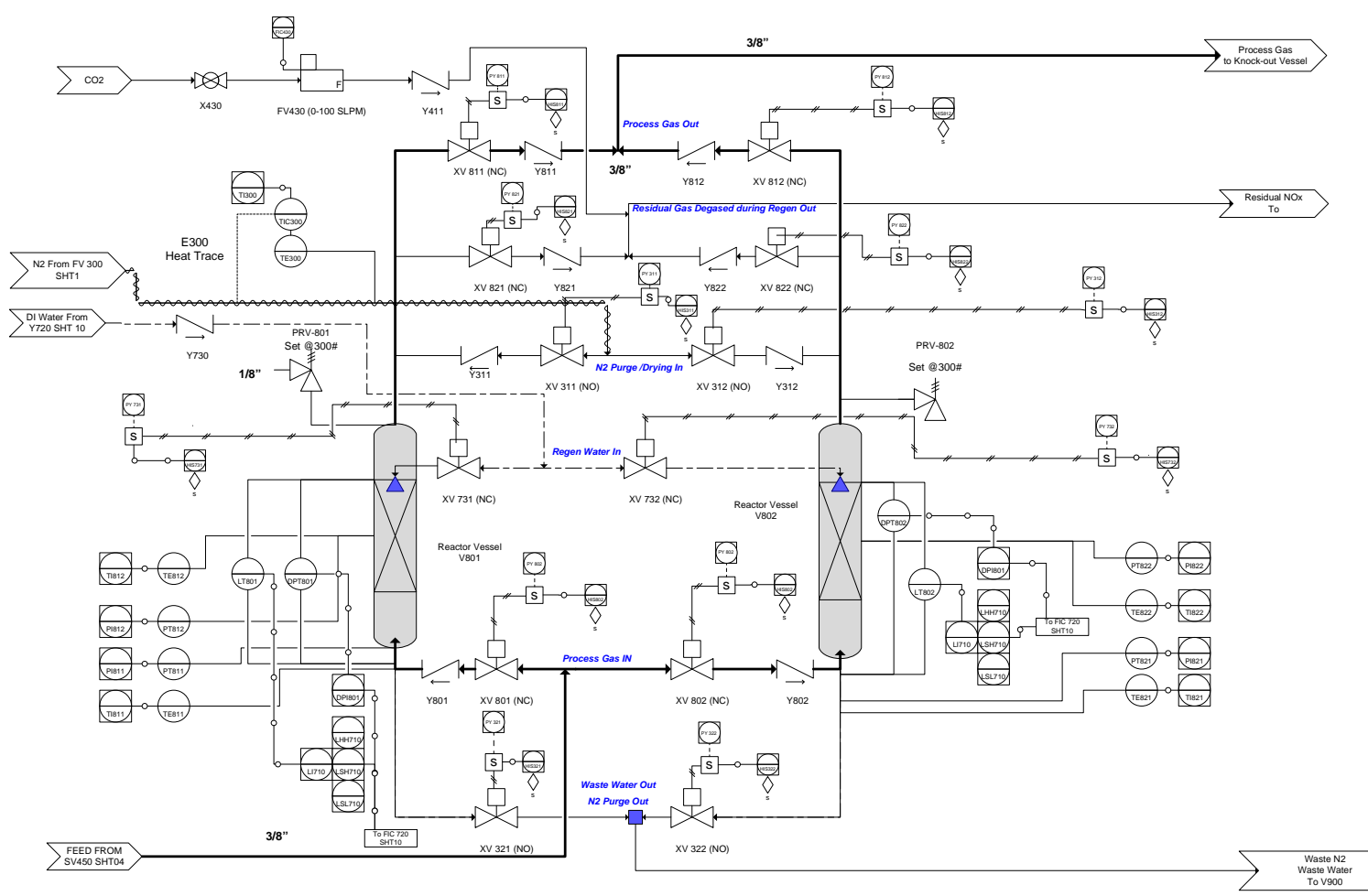

Figure 6. Dual Bed Reactor System for Simultaneous SOx/NOx Removal

The main goal of the experimental investigation is to understand how the carbon material capability to simultaneously remove traces of SOx and NOx evolve during a period of two months of continuous operation. The workflow for the proposed experimental program is given in Figure 7. 


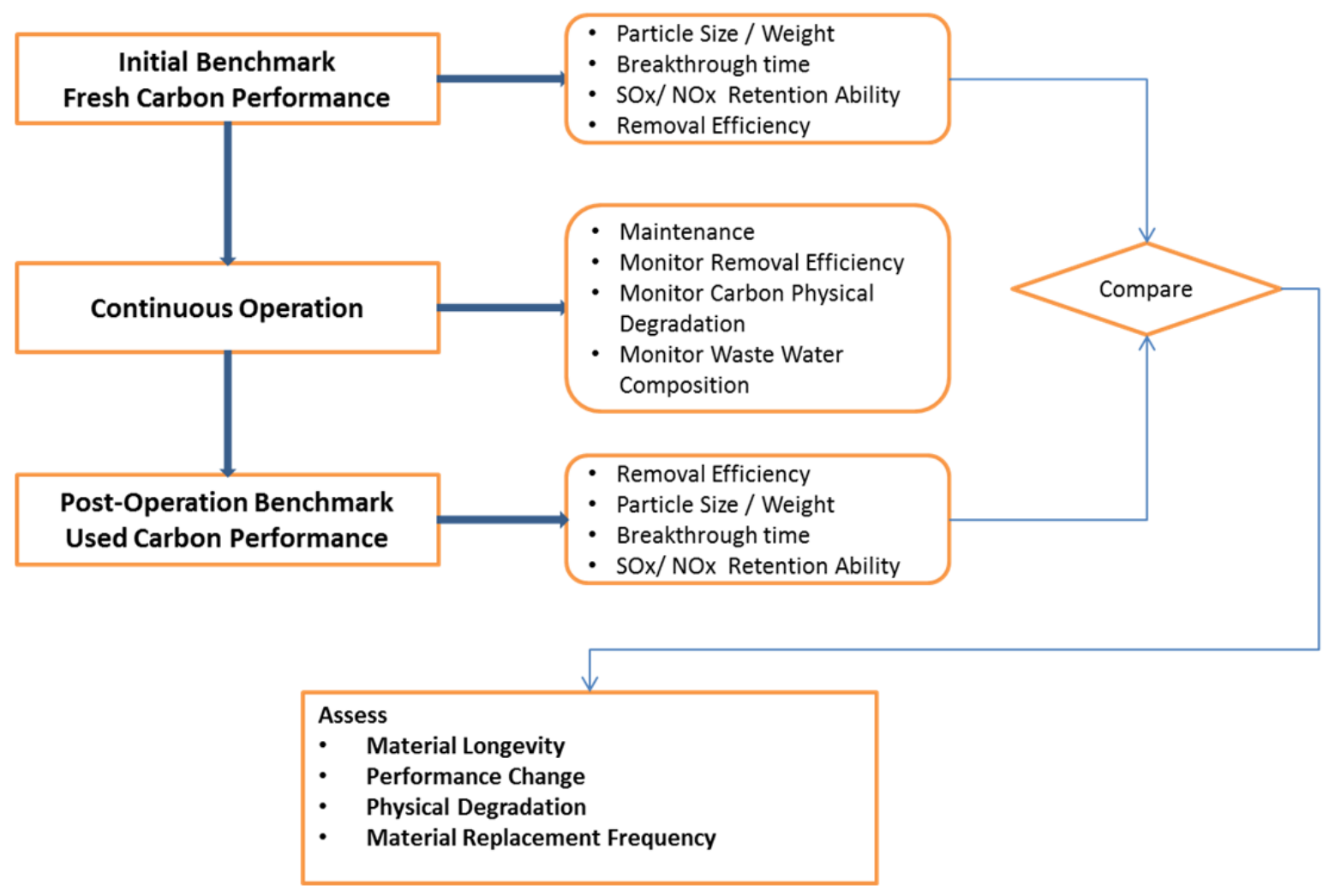

Figure 7. Workflow to Assess the Activated Carbon Material Longevity

First a benchmark is established for the fresh carbon. More specifically, the breakthrough time and consequently the initial amount of $\mathrm{SO}_{2}$ and $\mathrm{NO}$ retained per unit mass of activated carbon, was determined for a set of inlet conditions for both beds. For the benchmarking purpose, the adsorption stage was conducted till breakthrough of any of the contaminants occurred. In this particular study, the breakthrough time is considered to take place when any of the contaminants: $\mathrm{SO}_{2}$ or NOx concentration reaches $30 \mathrm{ppm}$ in the gas stream leaving the reactor skid.

After the benchmarking was defined, the unit operated almost continuously for 40 days. The advanced automation and safety features allowed the unit to run $24 \mathrm{~h} /$ day with minimum supervision and unattended during weekends. The outlet concentration of all components was monitored continuously. It was sought to understand primarily if continuous operation altered the carbon material performance.

In order to ensure the process continuity, two parallel beds were used. While one bed operated in adsorption mode, the second bed was regenerated. A generic operating schedule is given in Table 2. 
Table 2. Dual Bed Activated Carbon Unit Cycle Steps

\begin{tabular}{|l|c|c|c|c|c|}
\hline Cycle & \multicolumn{3}{|c|}{1} & \multicolumn{3}{c|}{2} \\
\hline Bed A & \multicolumn{2}{|c|}{ Adsorption } & Washing & Drying & Hold \\
\hline Bed B & Washing & Drying & Hold & \multicolumn{3}{c|}{ Adsorption } \\
\hline
\end{tabular}

Continuous operation was configured so that the adsorption stage duration was at least equal or higher than the duration of the regeneration (washing and drying of the other carbon bed). A continuous and smooth transition from the bed in service to the regenerated bed was achieved.

At the end of continuous operation period, a similar systematic evaluation of the breakthrough time, and SOx/NOx removal efficiency and capacity was reassessed. The results were compared with the initial benchmarking in order to conclude how the activated carbon material changed its capability to simultaneously remove SOx and NOx. 


\section{Results and Discussion}

\section{Subtask 3.1 - SOx and NOx Removal Material Selection}

Six samples of commercially available activated carbon were tested. Figure 8 compares the $\mathrm{SO}_{2}$ removal performance of these samples. The $\mathrm{SO}_{2}$ retention is calculated using equation (1) and then is scaled based to the best performance among all experiments. Figure 8 gives a comparison on relative bases for all samples investigated, and each cycle.

For the first cycle, the sample was loaded as received from the suppliers, while the following cycles are performed after the materials had undergone regeneration by water washing. No extensive drying was applied; therefore the moisture content in the bed in subsequent cycles was significantly higher as compared to the first cycle. This explains lower $\mathrm{SO}_{2}$ retention by the carbon bed in the first cycle as compared to the following 2 cycles.

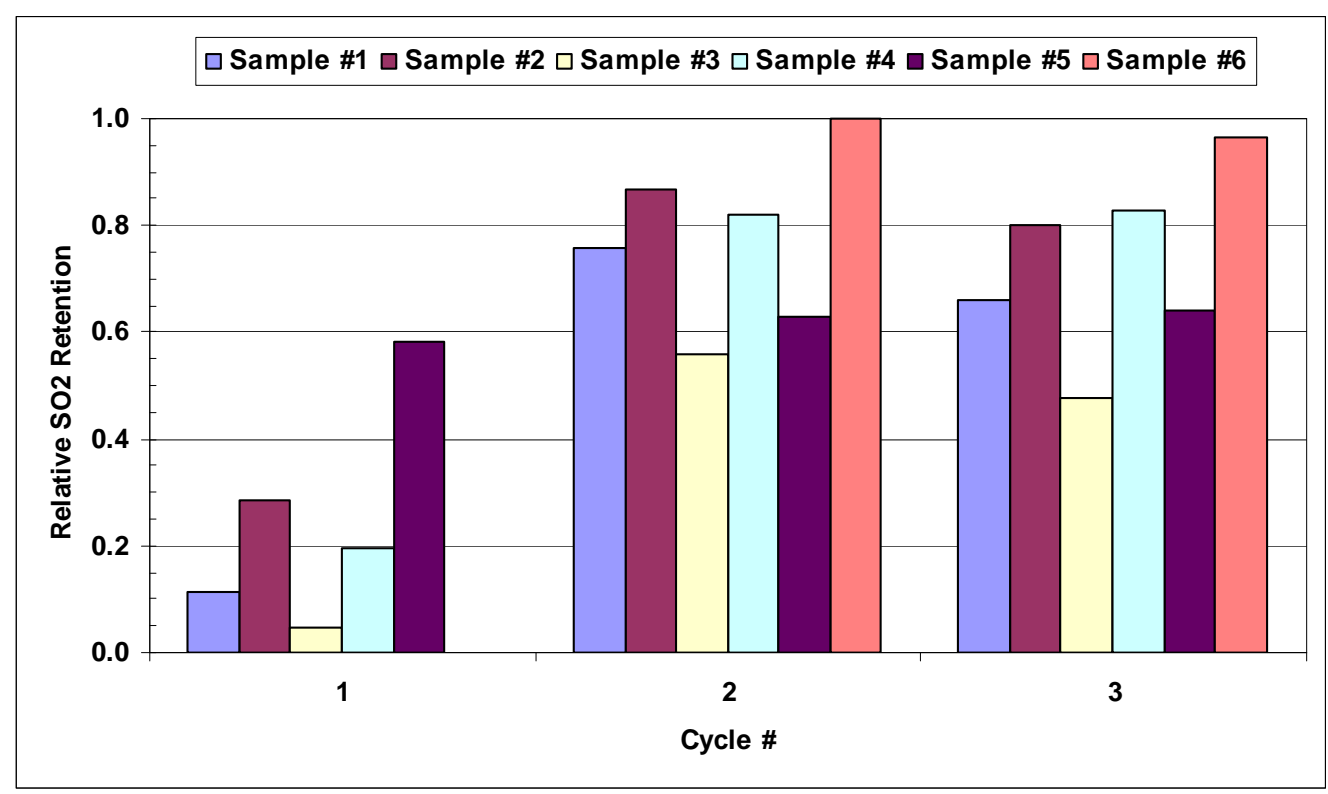

Figure 8. Relative Retention of $\mathrm{SO}_{2}$ for Different Activated Carbon Samples

The relative $\mathrm{SO}_{2}$ retention on the tested samples ranged from $0.55-1$ (excluding cycle 1 results). Considering the variations in test conditions, measurement errors and limited number of tests, the performance of these samples are considered comparable. Material represented by Sample \#2 was selected for simultaneous SOx and NOx removal in the bench unit designed and assembled as part of subtask 3.2.

\section{Subtask 3.2 - Design and Construction of the Bench Unit}

The bench unit for simultaneously SOx and NOx removal is shown in Figure 9. It had a compact lay-out to fit all the components in a designated hood. Easy access to all manual valves and instrumentation was available in order to maintain safe and efficient 
operation. The gas cabinets containing the cylinders with toxic gases for process investigation and calibration are shown in Figure 10. Also, Figure 10 shows on the right hand side the PLC box.

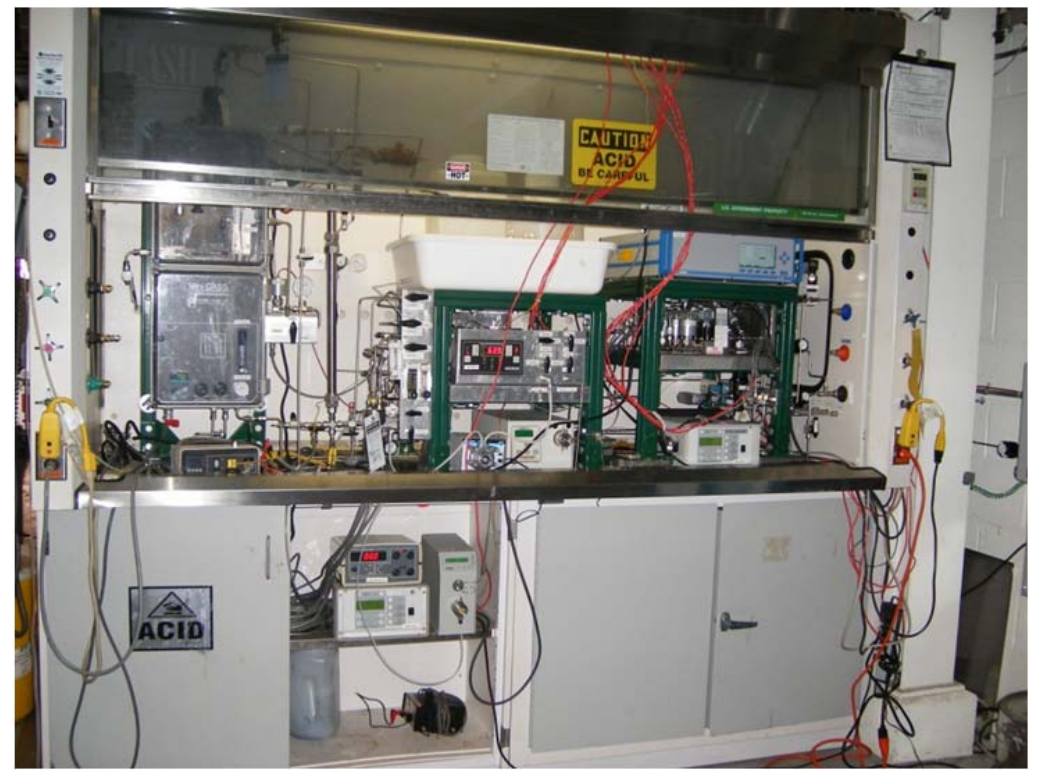

Figure 9. Bench Unit for Batch Mode Operation

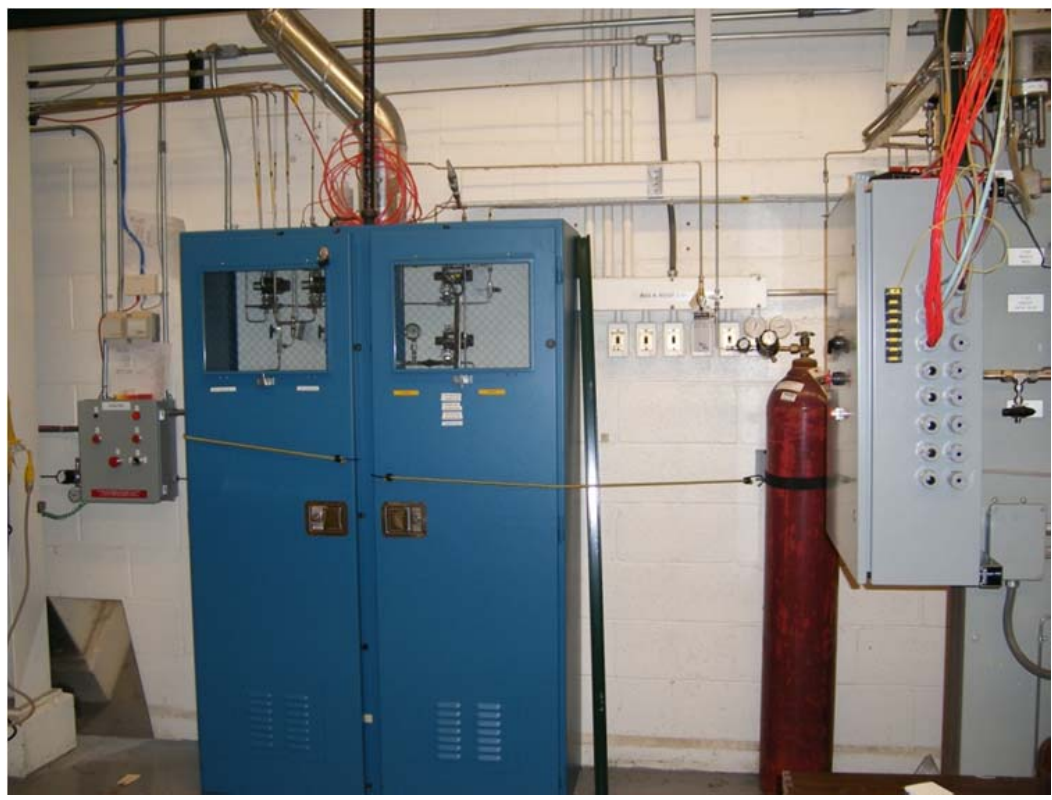

Figure 10. Gas Cabinet for Toxic Gas Cylinders Storage and PLC Box.

One of the challenges encountered during operation of the experimental set-up was related to the humidification of the feed stream. The initial solution was to inject a small amount of water to the main gas stream before entering the reactor. It was observed that the process water delivery and its vaporization prior to entering the reactor bed did not provide a constant flow and composition in the feed stream of the water vapors. To avoid 
this shortcoming, the system was modified to include a humidifier vessel. This enabled the $\mathrm{CO}_{2}$ stream to pass through a column of water and to saturate with water vapors. The humidifier vessel concept is shown in Figure 11. The vessel consists of pipe with 4" diameter and 3' height, and contains $0.5 \mathrm{l}$ water. The $\mathrm{CO}_{2}$ stream with flows in the range of 10-25 SLPM is fed through a $1 / 4$ " pipe and directed towards the bottom of the vessel. A sparger delivers the gas flow across the vessel cross-section. Steel wool is used as packing to ensure enhanced gas-liquid interfacial area. In this manner the gas bubbles through the liquid water from bottom to top, leaving the vessel close to saturation conditions. A baffle was provided to minimize the possibility of carrying liquid water along with the gas stream.

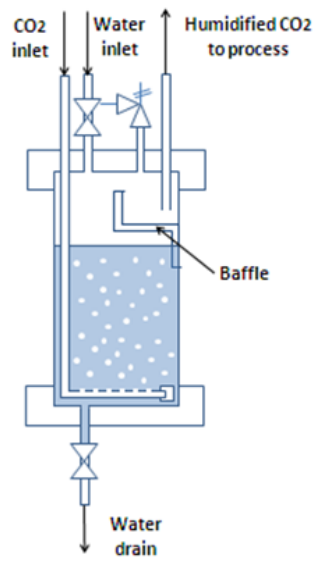

Figure 11. Schematic of $\mathrm{CO}_{2}$ humidifier

The water content in the $\mathrm{CO}_{2}$ stream was confirmed by performing humidity measurements using a Moisture Monitor Series 35 from Panametrics. The measurements showed good correlation with the theoretical saturation levels. This design was used for a more in-depth investigation of the water content impact on the process performance.

\section{Subtask 3.3 - SOx/NOx Removal Tests}

The results of a typical breakthrough test are shown in Figure 12 as time dependence of measured reactor outlet concentration for $\mathrm{SO}_{2}$ and NO. Usually the $\mathrm{NO}$ breaks through first and exhibits a gradual increase of outlet concentration as compared with $\mathrm{SO}_{2}$ which shows a sharper breakthrough. These breakthrough curves were used to calculate the retention and contaminants removal efficiency using the equations (1) - (3). 
Dry feed containing 750 ppm NO, 2000 ppm SO2, and 4 \% O2

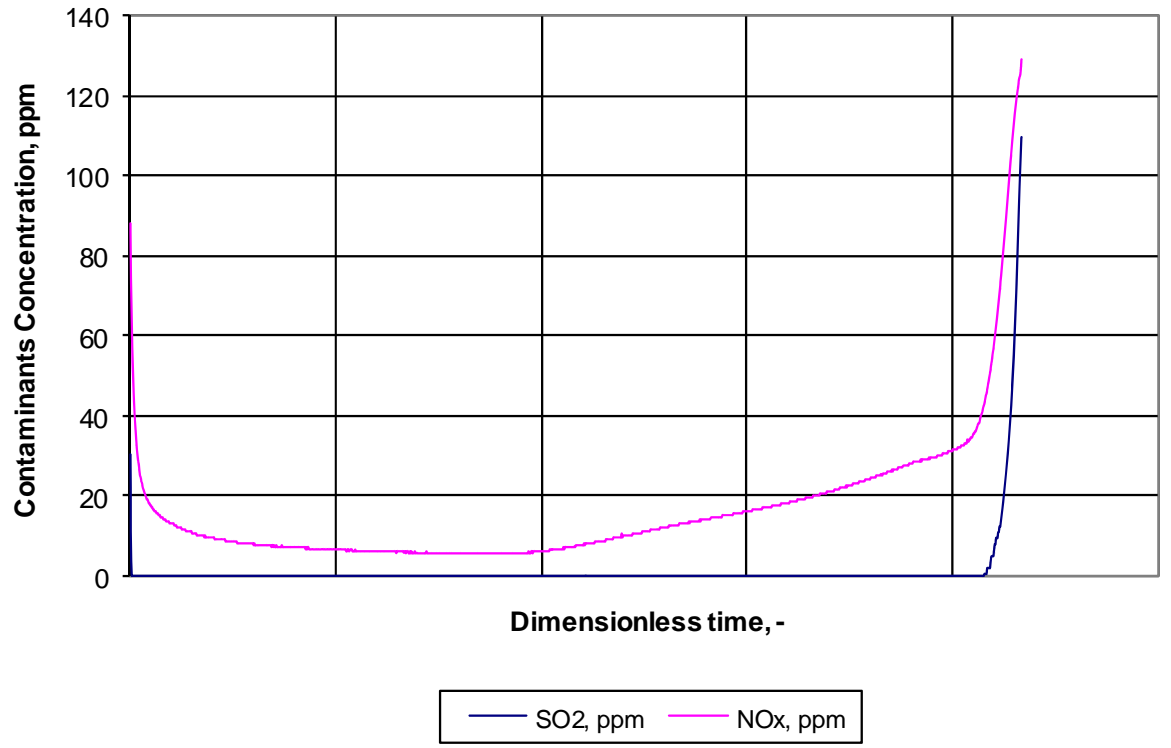

Figure 12. Reactor Outlet $\mathrm{SO}_{2}$ and NOx Concentrations as a Function of Time

The experimental results for each bed reported on relative bases are given in Table 3 . The retention values reported in Table 3 are scaled using the bed number 9 as benchmark. The molar retention considered is an average for the number of adsorption-regeneration cycles completed for each bed. In Table 3, columns I and J contain individual relative retentions of $\mathrm{NO}$ and $\mathrm{SO}_{2}$ respectively, while column $\mathrm{K}$ shows the combined relative retention. Columns $\mathrm{L}$ and $\mathrm{M}$ display the removal efficiency as calculated by equation (14). Overall the results obtained indicate a good simultaneous removal of SOx and NOx with efficiency higher than $99 \%$ for $\mathrm{SO}_{2}$ and $93 \%$ for NOx. The influence of the operating conditions investigated is discussed below. 
Table 3. Activated Carbon Process - Bench Unit Results

\begin{tabular}{|c|c|c|c|c|c|c|c|c|c|c|c|c|}
\hline $\begin{array}{l}\text { Bed } \\
\text { Index }\end{array}$ & $\begin{array}{l}\text { Total } \\
\text { Flow }\end{array}$ & \multicolumn{3}{|c|}{ Inlet Composition } & \multirow[t]{2}{*}{$\begin{array}{c}\mathrm{H}_{2} \mathrm{O} \text { in } \\
\text { Feed }\end{array}$} & \multirow{2}{*}{$\begin{array}{c}\text { Temp } \\
\text { C }\end{array}$} & \multirow{2}{*}{$\begin{array}{c}\text { Press. } \\
\text { psig }\end{array}$} & \multicolumn{3}{|c|}{$\begin{array}{l}\text { Relative Retention } \\
\text { (Benchmark Bed 9) }\end{array}$} & \multicolumn{2}{|c|}{ Efficiency } \\
\hline & SLPM & $\begin{array}{l}\mathrm{SO} 2, \\
\mathrm{ppm}\end{array}$ & $\begin{array}{l}\text { NO, } \\
\text { ppm }\end{array}$ & $\begin{array}{l}\mathrm{O} 2, \\
\%\end{array}$ & & & & NO & $\mathrm{SO}_{2}$ & $\mathrm{NO}+\mathrm{SO}_{2}$ & $\begin{array}{c}\text { NO, } \\
\%\end{array}$ & $\begin{array}{c}\mathrm{SO} 2, \\
\%\end{array}$ \\
\hline A & B & C & D & $\mathrm{E}$ & $\mathrm{F}$ & G & $\mathrm{H}$ & I & $\mathrm{J}$ & K & L & M \\
\hline 1 & 10 & 0 & 750 & 0 & No & 20 & 220 & 0.0 & NA & 0.0 & 0.00 & NA \\
\hline 2 & 10 & 0 & 750 & 4 & No & 20 & 220 & 1.7 & NA & 0.4 & 99.30 & NA \\
\hline 3 & 10 & 2000 & 750 & 4 & No & 20 & 220 & 1.0 & 0.9 & 0.9 & 97.33 & 99.99 \\
\hline 4 & 10 & 0 & 750 & 6 & No & 20 & 220 & 2.0 & NA & 0.5 & 97.20 & NA \\
\hline 5 & 10 & 2000 & 750 & 4 & No & 80 & 220 & 0.6 & 0.6 & 0.6 & 97.30 & 99.99 \\
\hline 6 & 10 & 0 & 750 & 6 & No & 80 & 220 & 1.1 & NA & 0.3 & 99.33 & NA \\
\hline 7 & 10 & 2000 & 0 & 4 & No & 20 & 220 & NA & 0.6 & 0.4 & NA & 99.99 \\
\hline 8 & 10 & 2000 & 750 & 4 & Yes & 20 & 220 & 1.6 & 1.6 & 1.6 & 97.30 & 99.99 \\
\hline 9 & 10 & 2000 & 750 & 4 & No & 20 & 220 & 1.0 & 1.0 & 1.0 & 97.50 & 99.99 \\
\hline 10 & 10 & 2000 & 0 & 4 & Yes & 20 & 220 & NA & 1.3 & 0.9 & NA & 99.99 \\
\hline 11 & 10 & 2000 & 0 & 4 & Yes & 20 & 220 & NA & 1.3 & 1.0 & NA & 99.99 \\
\hline 12 & 10 & 2000 & 750 & 4 & No & 20 & 220 & 1.0 & 0.9 & 0.9 & 99.80 & 99.99 \\
\hline 13 & 10 & 2000 & 0 & 4 & No & 20 & 220 & NA & 0.4 & 0.3 & NA & 99.99 \\
\hline 14 & 10 & 2000 & 750 & 4 & Yes & 20 & 220 & 1.0 & 1.0 & 1.0 & 97.60 & 99.99 \\
\hline 15 & 10 & 2000 & 750 & 4 & Yes & 20 & 220 & 1.8 & 1.8 & 1.8 & 98.05 & 99.98 \\
\hline 16 & 25 & 2000 & 750 & 4 & Yes & 20 & 220 & 1.0 & 1.0 & 1.0 & 96.95 & 99.97 \\
\hline 17 & 10 & 2000 & 750 & 4 & Yes & 20 & 50 & 0.3 & 0.3 & 0.3 & 93.04 & 99.97 \\
\hline 18 & 10 & 4000 & 210 & 4 & Yes & 20 & 220 & 0.1 & 0.9 & 0.7 & 93.90 & 99.99 \\
\hline 19 & 10 & 4000 & 510 & 4 & Yes & 20 & 220 & 0.4 & 1.1 & 0.9 & 96.94 & 99.98 \\
\hline 20 & 18 & 2000 & 750 & 4 & Yes & 20 & 220 & 0.9 & 0.9 & 0.9 & 94.72 & 99.97 \\
\hline 21 & 10 & 2000 & 750 & 4 & Yes & 20 & 150 & 0.7 & 0.8 & 0.8 & 97.45 & 99.98 \\
\hline 22 & 10 & 3000 & 510 & 4 & Yes & 20 & 220 & 0.4 & 0.9 & 0.8 & 97.55 & 99.98 \\
\hline 23 & 10 & 2000 & 750 & 4 & Yes & 20 & 100 & 0.6 & 0.6 & 0.6 & 96.70 & 99.97 \\
\hline
\end{tabular}

\section{Influence of Temperature}

Experiments were conducted at two different temperatures $80{ }^{\circ} \mathrm{C}$ and $20{ }^{\circ} \mathrm{C}$ respectively. It was observed that the activated carbon capacity to adsorb SOx and/ or NOx is almost doubled at ambient temperature than at $80{ }^{\circ} \mathrm{C}$ (see Figure 13). The removal efficiencies were higher than $97 \%$ for NOx and higher than $99 \%$ for SOx for both temperatures. 


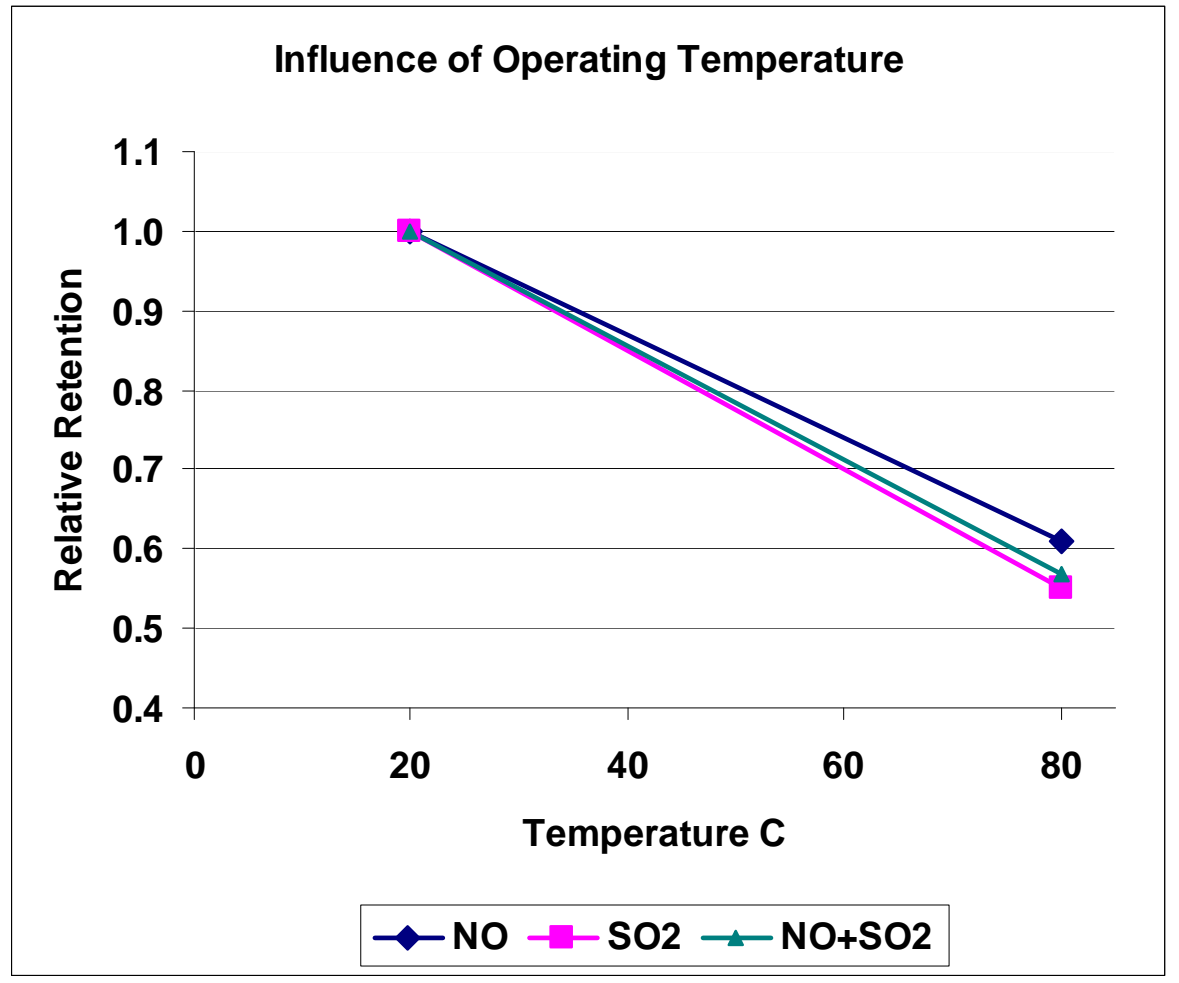

Figure 13. Influence of Temperature on Relative Retention of SOx and NOx

\section{Influence of Pressure}

Experiments were conducted at four different pressures 50, 100, 150, and 220 psig respectively. The activated carbon capacity to adsorb SOx and $\mathrm{NOx}$ significantly decreases with the decrease of pressure (see Figure 14). The $\mathrm{SO}_{2}$ removal efficiency is less impacted by the decrease in pressure. Removal efficiency higher than $99 \%$ is obtained for all pressures. The NO removal efficiency on the other hand is somehow more visible influenced by the decrease in pressure (see Figure 15). The NO removal efficiency is about $93 \%$ at 50 psig and it increases to $97.3 \%$ at 220 psig. This is a consequence of pressure influence on Reaction 1. 


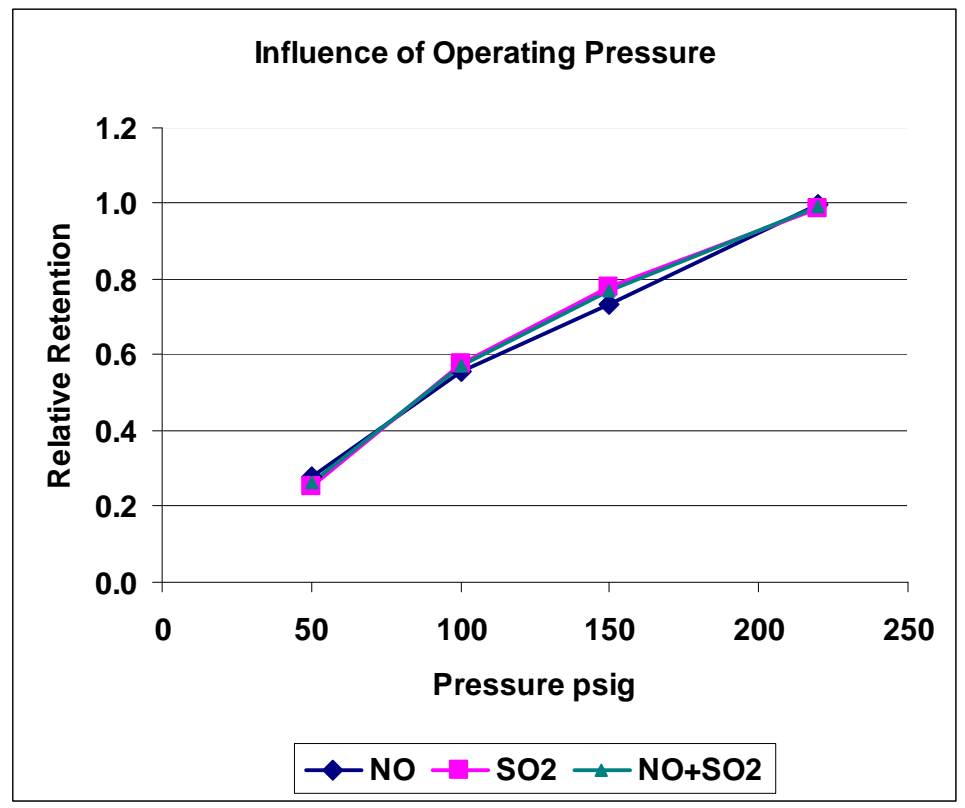

Figure 14. Influence of Operating Pressure on Relative Retention of SOx and NOx

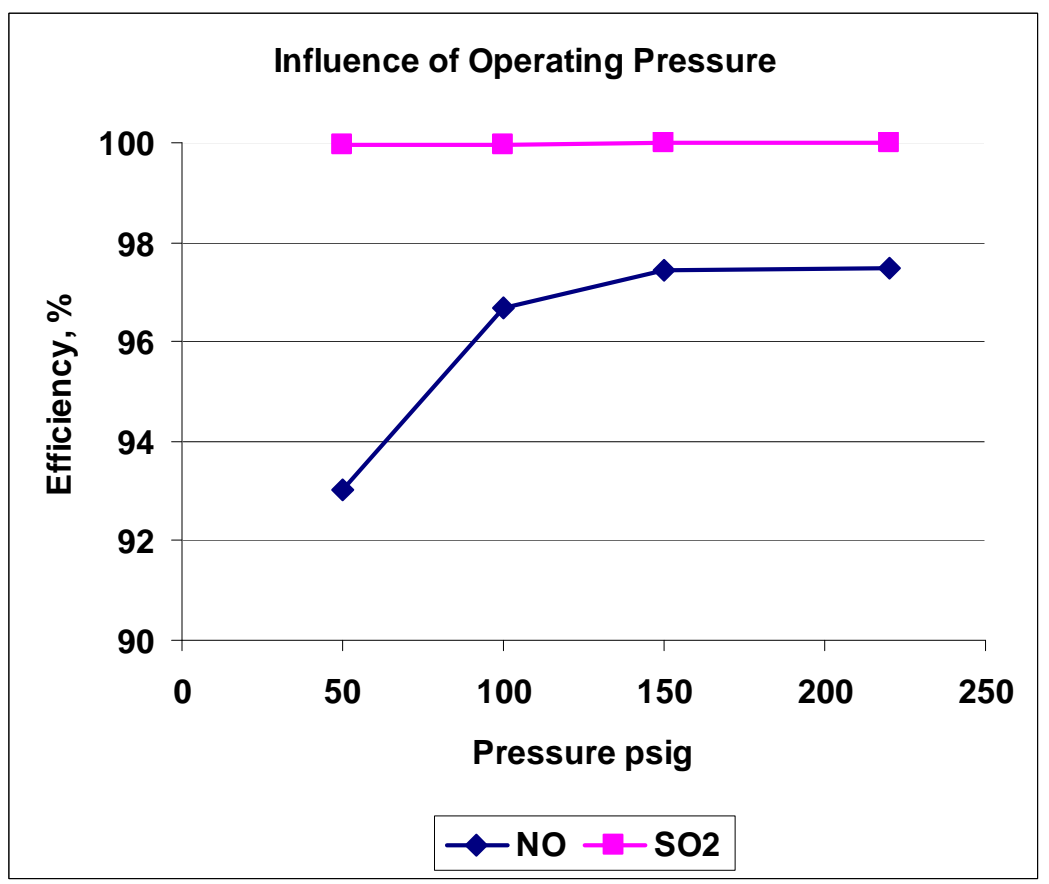

Figure 15. Influence of Operating Pressure on SOx and NOx Removal Efficiencies

\section{Influence of Inlet Composition}

Experiments were conducted at different $\mathrm{NO} / \mathrm{SO}_{2}$ inlet molar ratio in the range of 0 - 0.4 (see Figure 16). It was concluded that within this range a higher $\mathrm{NO} / \mathrm{SO}_{2}$ molar ratio is beneficial for individual and overall retention capacity of contaminants on activated carbon. This can be attributed to Reaction 9 which shows that there is an enhancement of $\mathrm{SO}_{2}$ oxidation in the presence of $\mathrm{NO}_{2}$, while the $\mathrm{NO}$ oxidation and adsorption is inhibited 
by $\mathrm{SO}_{2}$ presence. The $\mathrm{NO} / \mathrm{SO}_{2}$ inlet molar has little effect on $\mathrm{SO}_{2}$ removal efficiency. A lower $\mathrm{NO} / \mathrm{SO}_{2}$ inlet molar leads to slightly lower removal efficiency of the NO (see Figure 17).

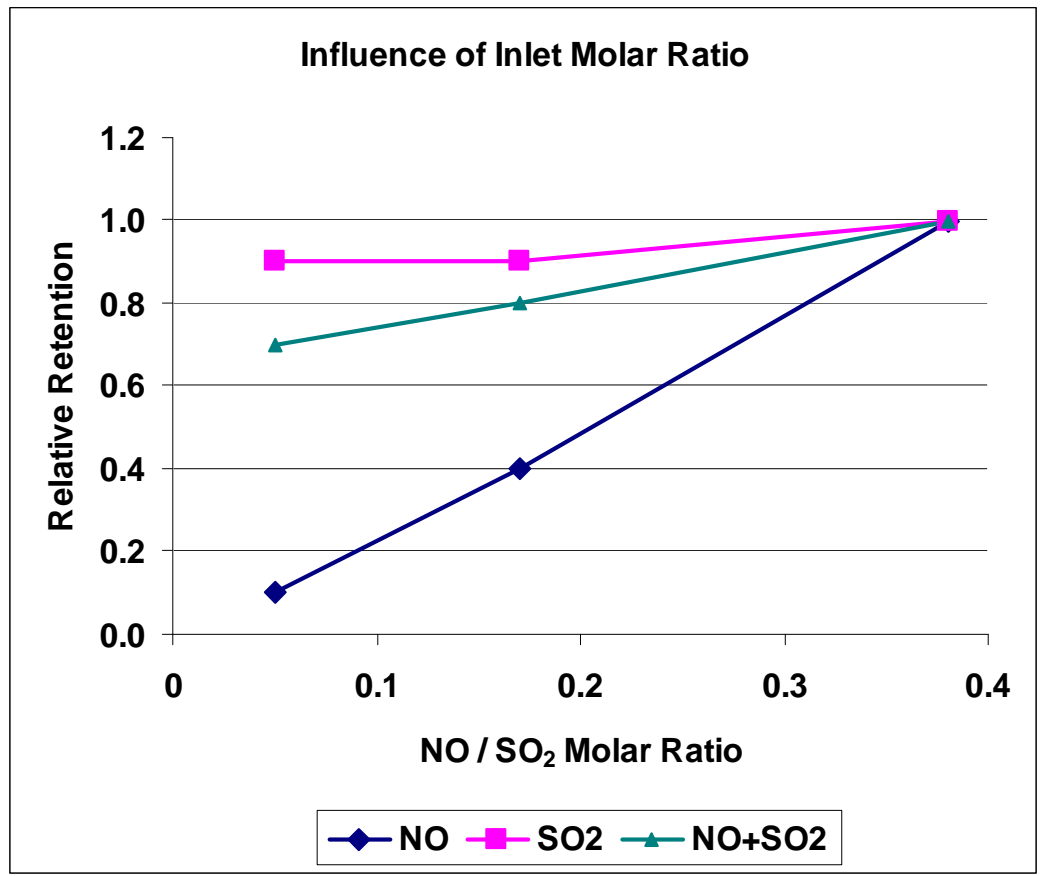

Figure 16. Influence of $\mathrm{NO} / \mathrm{SO}_{2}$ Molar Ratio in Feed on Relative Retention

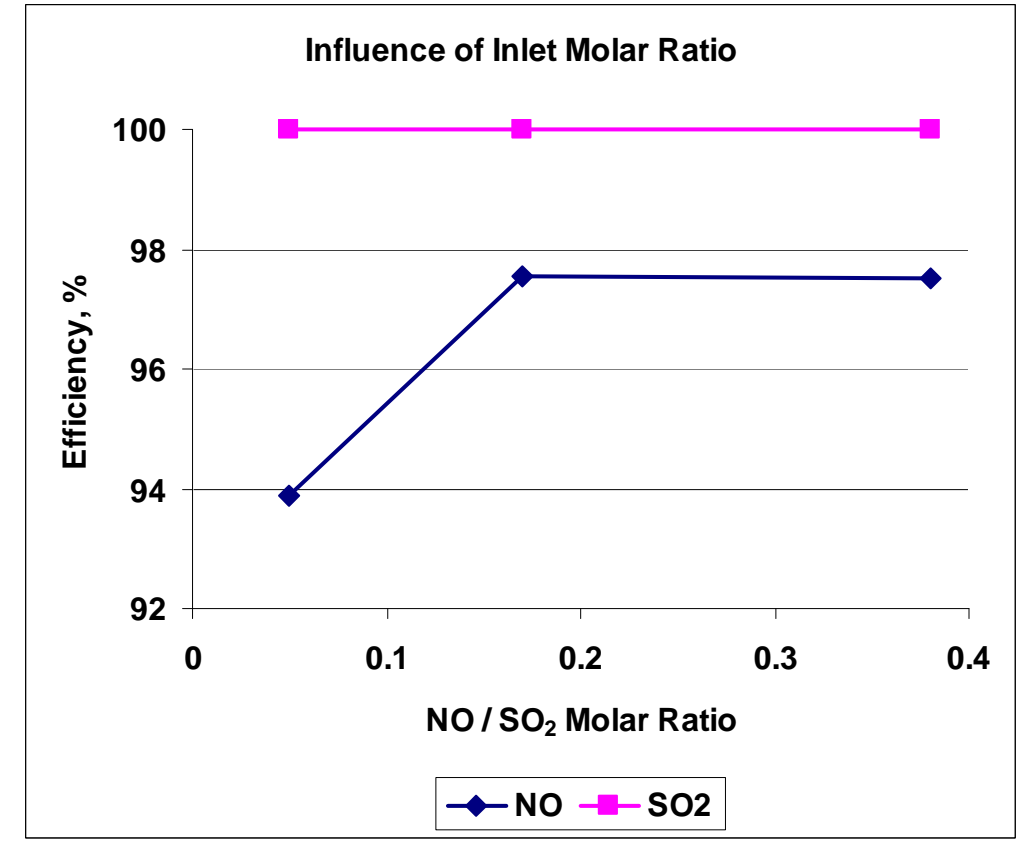

Figure 17. Influence of $\mathrm{NO} / \mathrm{SO}_{2}$ Molar Ratio in Feed on Removal Efficiency 


\section{Influence of Water}

Water presence in the simulated flue gas stream enhances $\mathrm{SO}_{2}$ removal through Reactions 3-8. Based on the experimental results obtained, it can be concluded that as long as water vapors are present in the feed at a concentration lower or closed to $\mathrm{SO}_{2}$ concentration, they have a positive effect on simultaneous SOx/NOx removal. Excess water concentration in the gas phase may initiate Reaction 11 which can inhibit the removal of NOx during the adsorption stage.

\section{Influence of residence time}

The effect of residence time on the overall retention of the contaminants on the activated carbon bed is not significant. The results indicate that the differences between the retentions for different gas flowrates, and similar temperature, pressure and inlet composition are within the experimental error (see Figure 18).

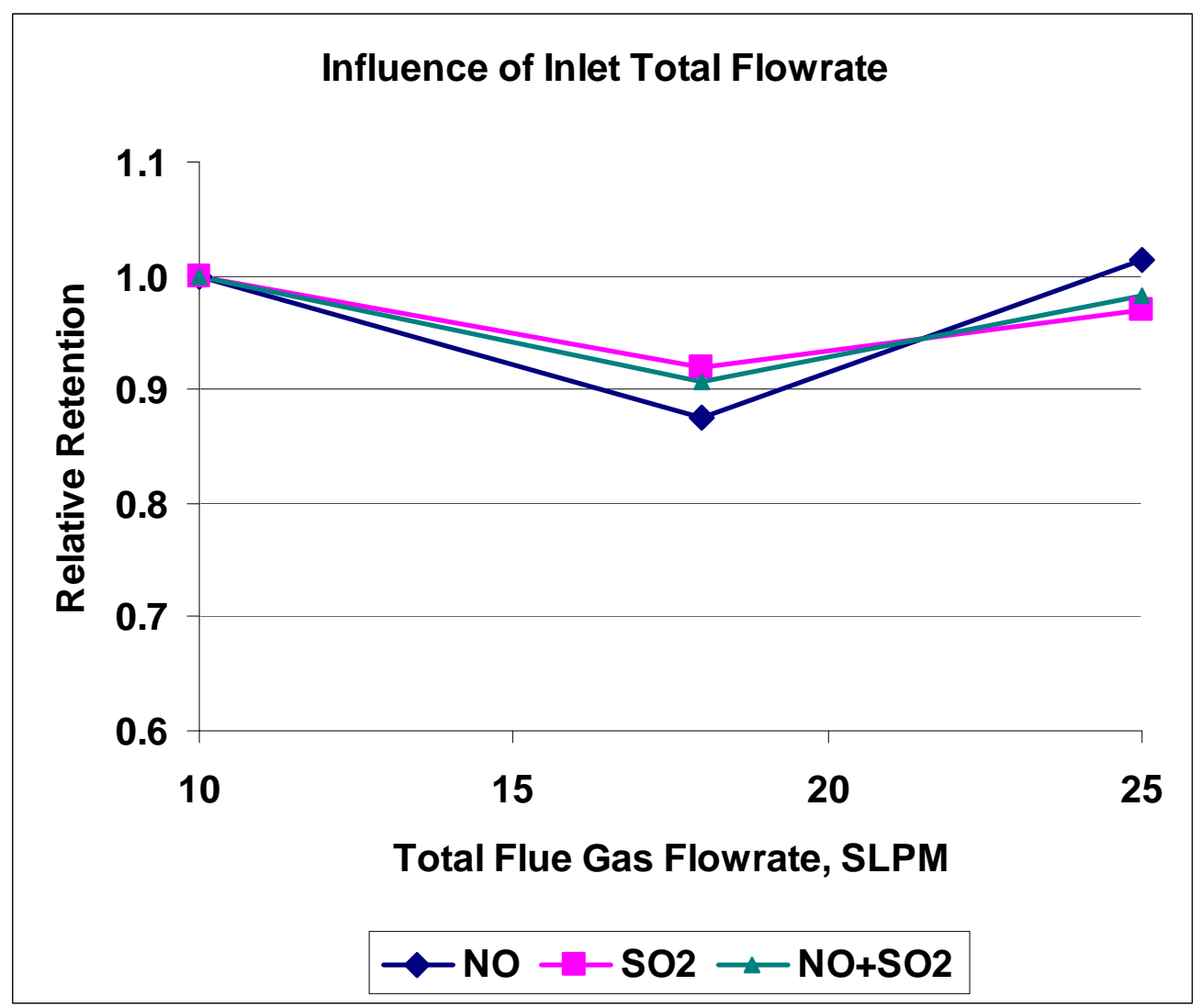

Figure 18. Influence of Total Feed Flowrate on Relative Retention

\section{Waste Water Analysis}

Waste water analysis was contracted to IsleChem LLC to determine the content of sulfate, sulfite, nitrate and nitrate for selected experiments using ion chromatography. The results indicate that most of the SOx species (more than $99 \%$ ) adsorbed on the activated carbon were found in the waste water stream in the form of sulfates and sulfites. The nitrogen species found the waste water stream are nitrates and nitrates and 
correspond to less than $60 \%$ of the NO adsorbed on carbon. This support the findings previously discussed that during the regeneration period part of the $\mathrm{NO}_{2}$ is converted back to NO.

\section{Material Longevity Investigation}

The bench unit was used to briefly investigate material longevity in batch mode operation, by repeating the adsorption regeneration cycles. For this purpose, a carbon bed was exposed to the conditions given for bed 9 in Table 3. After about 20 cycles of adsorption - regeneration, material performance remained unaltered.

\section{Subtask 3.4 - Mercury and Residual NOx Removal Research:}

Mercury in the flue gas usually exists in three forms: oxidized $\left(\mathrm{Hg}^{2+}\right.$, usually as $\mathrm{HgCl}$, $\mathrm{HgO}$, and $\mathrm{HgS})$, elemental $\left(\mathrm{Hg}^{\circ}\right)$ and particle-bound $\left(\mathrm{Hg}^{\mathrm{P}}\right)$. Due to its high volatility, mercury usually exists in vapor form. Oxidized mercury is soluble in water and can be removed through its dissolution in water [3]. Relative amount of different mercury forms present in the flue gas depends on coal type and combustion systems. Studies done on pilot and full-scale systems indicated that amount of oxidized mercury ranges from 10$80 \%$ of the total vapor phase mercury [4, 5 and 6$]$.

There are three locations where mercury can be captured in the CPU: compression stage, moisture removal stage, and within the activated carbon process stage during the regeneration stage, when the acidic waste water can dissolve most of the mercury left in the gas stream. Additionally, a polishing step using sulfur impregnated activated carbon can be used before the cold box for final mercury removal.

\section{Subtask 3.5 - Continuous Operation Unit}

\section{Continuous Unit Construction}

The continuous unit is shown in Figure 19. The reactor skid was located in the center of the hood; the supply skid was located at the right end, while the analytical skid is shown at the left end.

The MFCs for gas metering were located at the bottom of the skid, while the liquid $\mathrm{SO}_{2}$ pump, the water process pump, and water pump for regeneration were mounted at the top of the supply skid. This also contained the humidifier. The water pump for the discharge of the waste water vessel, which can be seen between the analytical and the reactor skid, was mounted at the bottom of the reactor skid. The analyzers were located at the bottom of the analytical skid, while the sample conditioning units for drying the gas samples before sending them to the analyzers can be seen mounted on the upper side of the skid. 


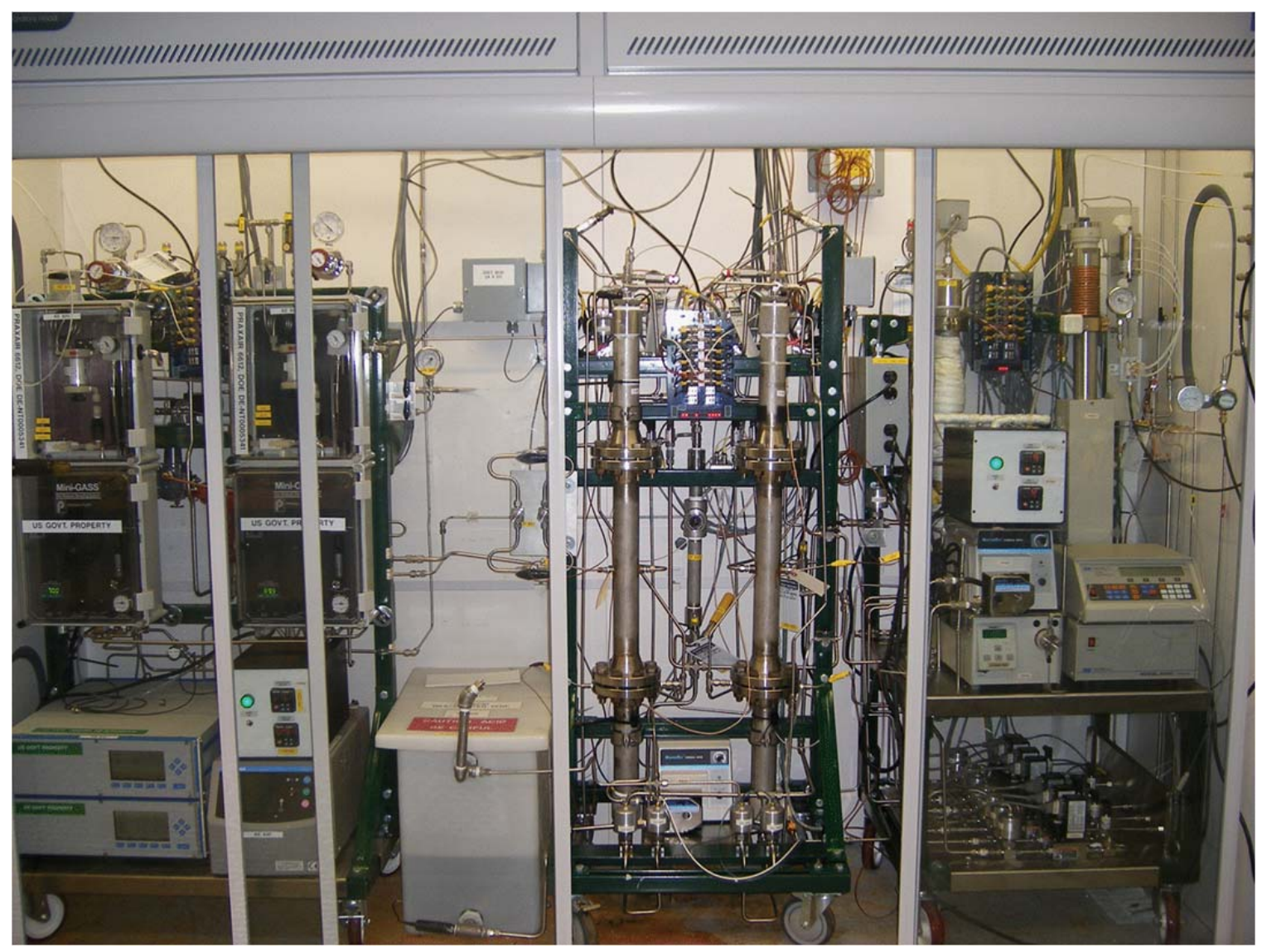

Figure 19. Dual Bed Continuous Operation Unit

\section{Continuous Unit Commissioning}

Testing of Regeneration Stage

Regeneration consisted of washing the carbon material with water, to remove the contaminants in the form of their corresponding acids: $\mathrm{H}_{2} \mathrm{SO}_{4}$, and $\mathrm{HNO}_{3}$, followed by a drying step to remove the water from the carbon material. The water was fed from bottom to top to avoid channeling and to ensure complete filling of the vessel's volume. The water was kept in the vessel for 10 min to allow enough time for acids formation and their dissolution in the washing water. The waste water was drained pressurizing with nitrogen. Initial tests were conducted to understand the functionality of the regeneration sequence and the required time to complete one regeneration stage.

Figure 20 shows the temperature profile during the regeneration stage. It can be seen that first, due to the depressurization of the bed, the temperature dropped below the ambient. For each water washing step, a slight increase in temperature is observed. This corresponds to the formation of sulfuric and nitric acids which are exothermic reactions. After the washing was completed, nitrogen was flown through the bed for drying. A heating tape was used to preheat nitrogen to 300F before entering the reactor. The temperature profiles depicted in Figure 20 indicate that as water was evaporated the carbon bed started to heat up gradually. A spike in temperature occurred when most of 
the water was removed. About 3-4 hours are required for the bed to dry. A cooling period was allowed to avoid starting the adsorption stage with the activated carbon material at temperatures above ambient.

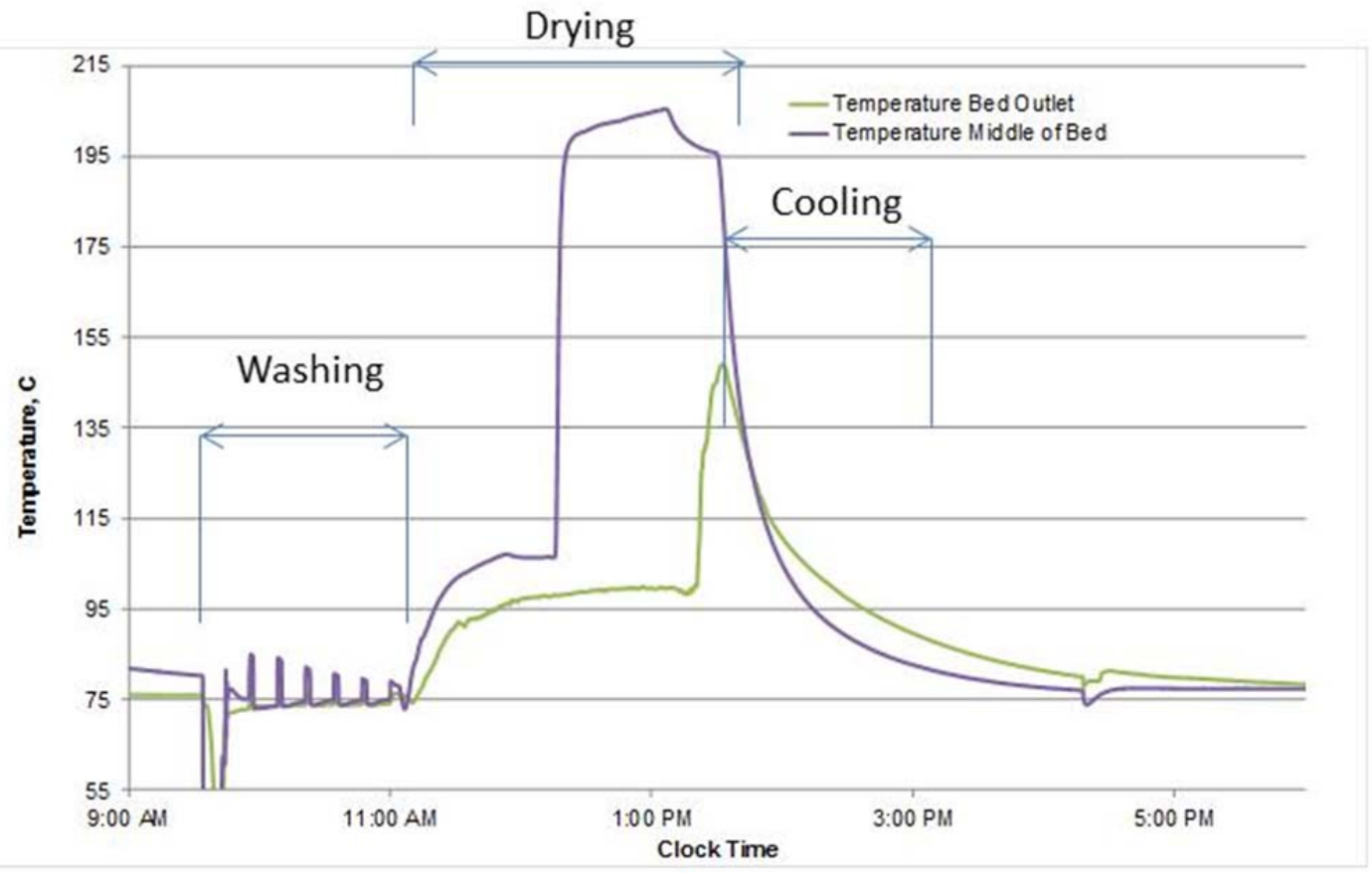

Figure 20. Temperature Profiles During the Regeneration Stage

Samples of waste water were collected for each six discharges. Each sample was analyzed for its content in $\mathrm{SO}_{4}{ }^{2-}$, and $\mathrm{NO}_{3}{ }^{-}$ions in order to understand the efficiency of regeneration. Semi-quantitative colorimetric methods based on a HACH 890 colorimeter (methods 8051, 10020, and 8153) were used.

Figure 21 shows for example the depletion of the sulfate ion concentration with the number of washes. A two order of magnitude decrease was observed. This is an indication of almost complete removal of sulfates through six consecutive washes. 


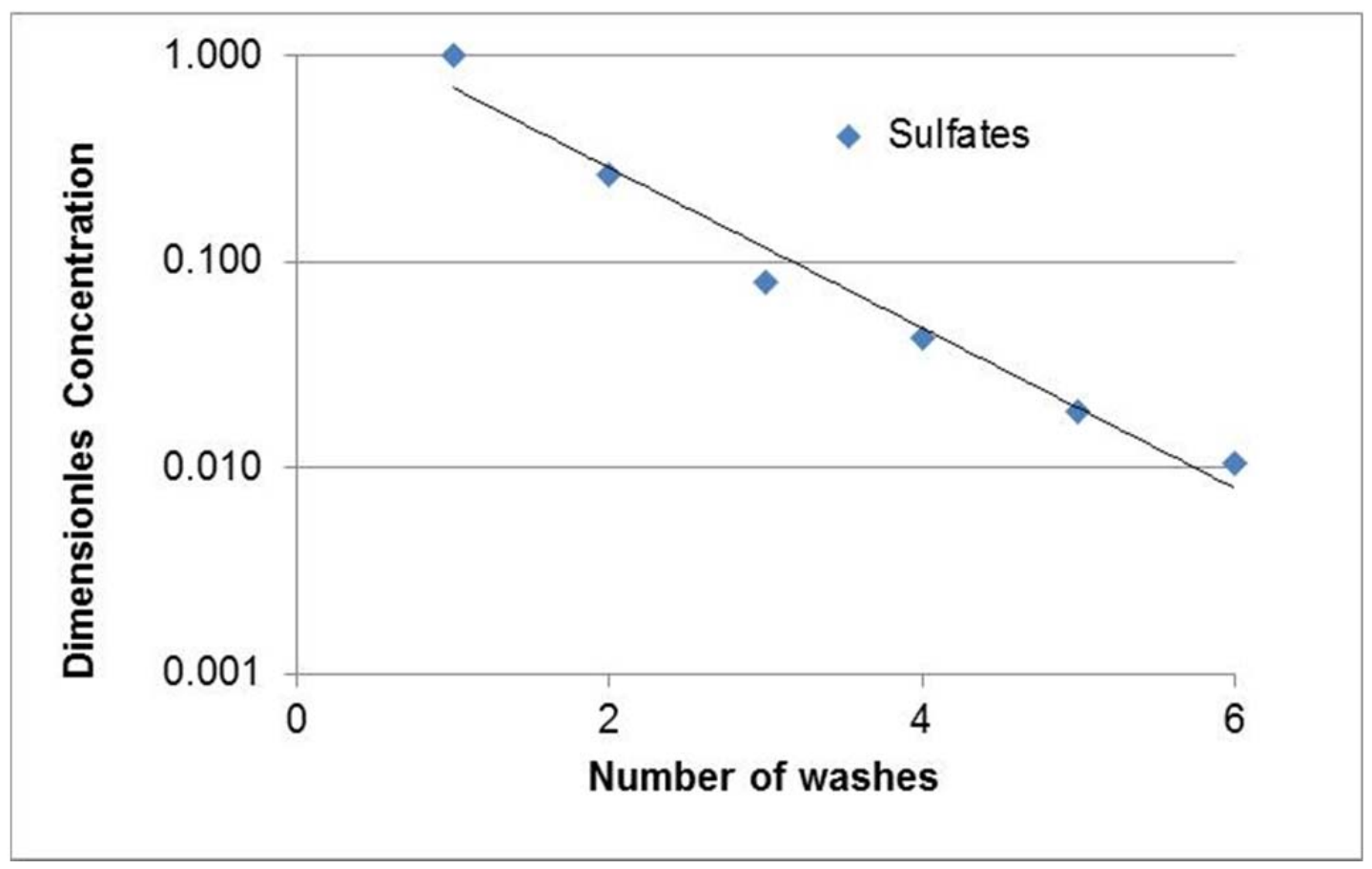

Figure 21. Depletion of Sulfate Ions in Waste Water with the Number of Washes

\section{Testing of Adsorption Stage}

The simulated flue gas stream was obtained by mixing the following components: $100 \%$ $\mathrm{CO}_{2}$ (gas), 3\% NO in Nitrogen (gas), $\mathrm{O}_{2} 100 \%$ (gas) and $100 \% \mathrm{SO}_{2}$ (liquid). A Teledyne ISCO 500 high pressure high precision pump was used for liquid $\mathrm{SO}_{2}$ delivery. Several runs using liquid $\mathrm{SO}_{2}$ as source showed that pumping and vaporizing the $\mathrm{SO}_{2}$ into the simulated flue gas mixture was challenging. Although the pump had good accuracy, $\mathrm{SO}_{2}$ flashes within the pump itself leading to uneven flow supply and misleading metering of the amount of $\mathrm{SO}_{2}$ delivered. Modifications were made to use a gas source of $3 \% \mathrm{SO}_{2}$ in $\mathrm{N}_{2}$, which gave a more stable feed delivery and composition.

The benchmark evaluation was performed for a simulated flue gas containing: $450 \mathrm{ppm}$ $\mathrm{SO}_{2}, 200 \mathrm{ppm} \mathrm{NO}, 4 \% \mathrm{O}_{2}, 94 \% \mathrm{CO}_{2}$ and $\mathrm{N}_{2}$ as balance, operating at 220 psig and close to the ambient temperature. The gaseous feed was saturated with water. First adsorption cycle on each bed was carried out for 30 hours each. No breakthrough was observed in this time indicated high level of retention capacity of the carbon. Outlet concentrations of the main components from bed 801 during second adsorption cycle are shown in Figure 22 as a function of running time. 


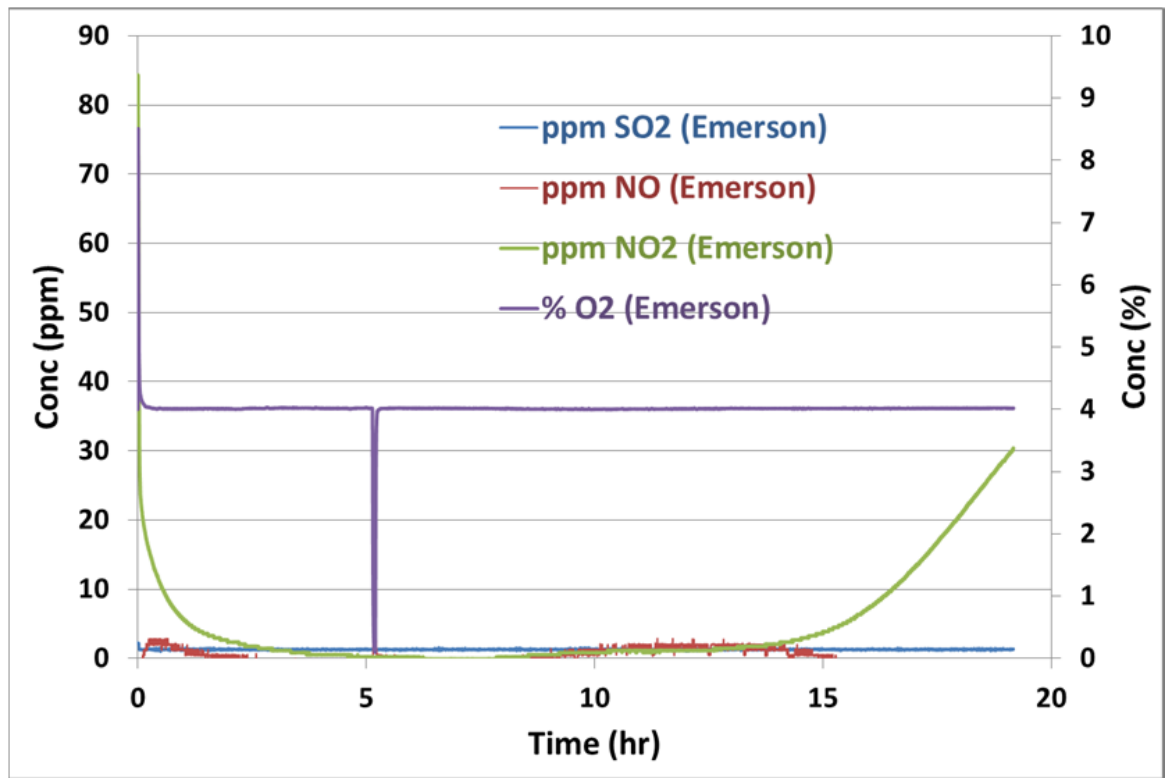

Figure 22. Reactor Effluent Concentrations as a Function of Time

It can be seen that for the selected conditions the breakthrough time is about 19 hours. The $\mathrm{SO}_{2}$ and $\mathrm{NO}$ concentrations in flue gas exiting the reactor remained low below $5 \mathrm{ppm}$ for the whole run, while $\mathrm{NO}_{2}$ stayed below $5 \mathrm{ppm}$ for $\sim 14$ hours after which it started to appear at the reactor exit. Thus $\mathrm{NO}_{2}$ is the first contaminant to breakthrough. For the entire run, $\mathrm{SO}_{2}$ and $\mathrm{NOx}\left(\mathrm{NO}+\mathrm{NO}_{2}\right.$ ) removal efficiency was $\sim 100 \%$ and $\sim 98 \%$ respectively.

During the commissioning and initial experimental tests other operating issues were identified. One important aspect was related to beds depressurization. Sudden pressure release had a severe impact on the activated carbon. Material dusting was observed, most probably induced by gas-solid friction and sudden temperature drop. Modifications were implemented to achieve a gradual change in pressure when the feed was switched between beds, or for shut-down.

\section{Continuous Unit Operation and Material Longevity Testing}

In order to study the longevity of the carbon material, adsorption / regeneration cycles (as shown in Table 2) were repeated 24/7 for 40 days. A log of outlet concentrations of main components was maintained to see the impact of repeated cycles on breakthrough time and thus on retention capacity of the carbon. Cycle times were set such that a clear breakthrough of contaminant was observed and beds were switched only after breakthrough occurred. For the purpose of analyzing bed's retention capacity, 30ppm of $\mathrm{NO}_{2}$ at the reactor exit was used to mark the end of adsorption cycle.

During the entire run of 40 days, $\mathrm{SO}_{2}$ and NO removal efficiency of $\sim 100 \%$ and $97-98 \%$ was observed respectively. Figure 23 shows breakthrough time for bed 801 after several repeated adsorption / regeneration cycles. For the first adsorption cycle breakthrough was not seen even after 30hrs of adsorption time (not shown in Figure 23). In the second 
cycle, breakthrough time decreased to $\sim 19$ hours. It can be observed that during the course of 40 days breakthrough time gradually dropped down from $20 \mathrm{hr}$ to $10 \mathrm{hr}$. The drop was steep till $12^{\text {th }}$ cycle after which it was more gradual. Similar results were observed for bed 802 .

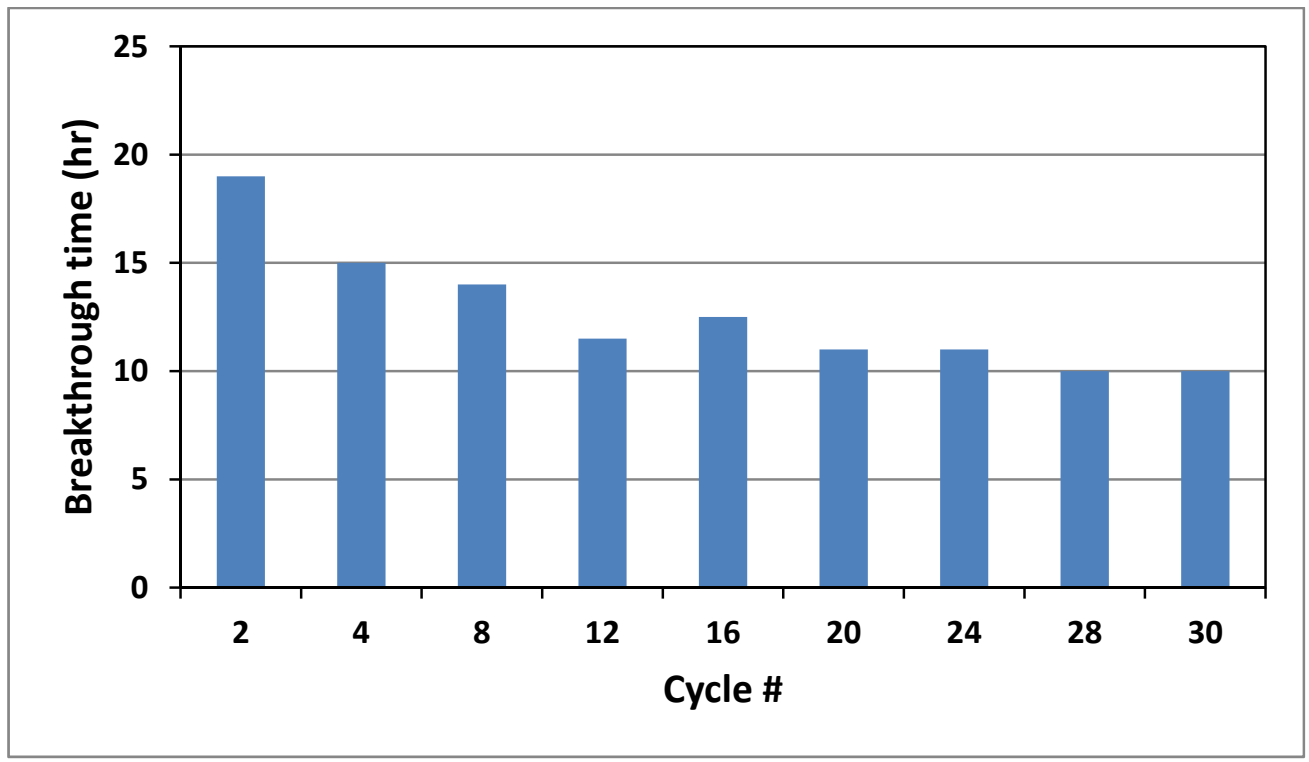

Figure 23. Breakthrough Time for Bed 801

Table 4 shows the removal efficiency of SOx and NOx during adsorption cycles for bed 801. Over 40 day period, removal efficiency of SOx and NOx was $>99 \%$ and $>98 \%$ respectively. Similar efficiencies were observed for bed 802.

Table 4. Removal Efficiency for Bed 801 over 40 Days of Continuous Operation

\begin{tabular}{|c|c|c|}
\hline \multirow{2}{*}{ Cycle \# } & \multicolumn{2}{|c|}{ Removal efficiency } \\
\cline { 2 - 3 } & SOx & NOx \\
\hline 2 & 99.8 & 99.1 \\
\hline 4 & 99.9 & 98.2 \\
\hline 8 & 100 & 98.5 \\
\hline 12 & 100 & 97.4 \\
\hline 16 & 100 & 98.1 \\
\hline 20 & 99.6 & 98.8 \\
\hline 24 & 99.6 & 98.9 \\
\hline 28 & 99.4 & 99.0 \\
\hline 30 & 99.6 & 98.8 \\
\hline
\end{tabular}

Outlet concentrations of the main components from bed 801 during 30th adsorption cycle (last cycle) are shown in Figure 24 as a function of running time. Breakthrough time dropped to $\sim 10$ hours indicating significantly reduced retention capacity of the activated 
carbon compared to benchmark. During the entire run $\mathrm{SO}_{2}$ and $\mathrm{NO}$ concentrations in flue gas exiting the reactor remained low below $5 \mathrm{ppm}$. As seen in the benchmark, $\mathrm{NO}_{2}$ was the first contaminant to breakthrough and it started to appear at the reactor exit only after $\sim 6$ hours but stayed below 10ppm until 9.5 hours. This suggests that despite the reduced retention capacity removal efficiency of the bed was unchanged. $\mathrm{SO}_{2}$ and $\mathrm{NOx}$ removal efficiency was $\sim 100 \%$ and $\sim 98 \%$ respectively.

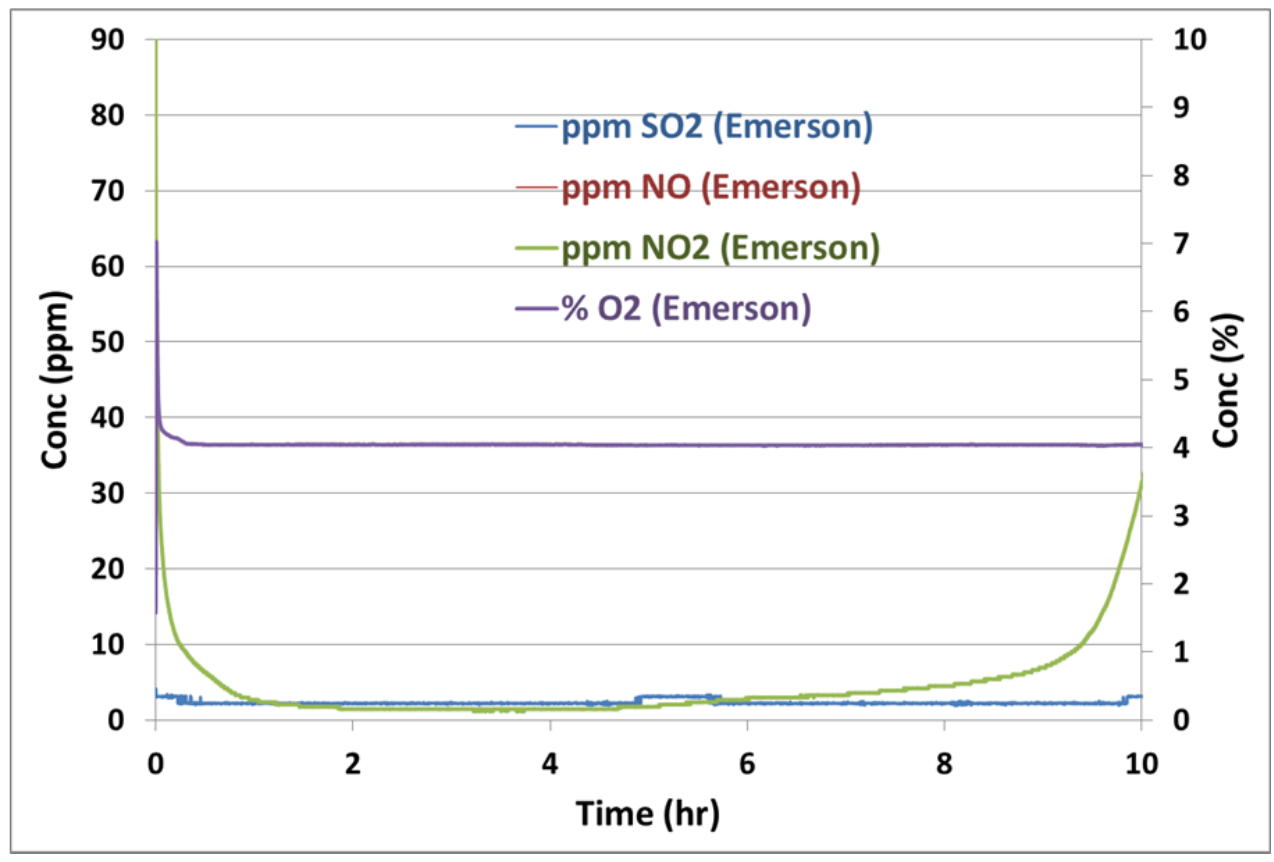

Figure 24. Reactor Effluent Concentration Profiles for 30th Adsorption Cycle

Such drop in breakthrough time was not observed for a feed with 2000ppm $\mathrm{SO}_{2}$ and $750 \mathrm{ppm}$ NO when it was tested on a bench unit for 20 cycles. For each cycle, breakthrough time was $\sim 7.5$ hours. When continuous run is compared against the bench scale study, there were several differences in the adsorption and regeneration steps due to differences in relative flow rates, bed volumes and regeneration times. In continuous run, during initial cycles of adsorption carbon bed was exposed to contaminants for very long time. This over exposure might have led to irreversible adsorption of contaminants leading to reduced active sites per unit volume of bed. In the regeneration step, much higher heating temperatures were used in the continuous unit compared to those in the bench scale testing.

In order to verify the structural stability of carbon, a BET analysis was performed. BET analysis provides precise specific surface area evaluation of materials by nitrogen multilayer adsorption measured as a function of relative pressure using a fully automated analyzer. The technique encompasses external area and pore area evaluations to determine the total specific surface area. The BET surface areas of carbon before and after continuous run were $745 \mathrm{~m}^{2} / \mathrm{g}$ and $677 \mathrm{~m}^{2} / \mathrm{g}$, respectively. Within the experimental errors this small drop in surface area is negligible. This indicates that the pore structure of carbon was intact during the repeated adsorption-regeneration cycles. 
In order to check any irreversible adsorption of contaminants on the carbon surface, ion chromatography was performed on spent carbon. Spent carbon was combusted in a pressurized decomposition vessel with oxygen atmosphere. The combustion gases are scrubbed using a gas washing bottle containing a solution of $\mathrm{NaHCO}_{3} / \mathrm{Na}_{2} \mathrm{CO}_{3}$. The scrubber solution is then analyzed for nitrate and sulfate by ion chromatography. The nitrate and sulfate content of the scrubber solution is used to calculate total nitrate and sulfate content of the carbon sample. It was found that total nitrate and sulfate content of the spent carbon was $3.7 \%$ and $2.3 \%$ by weight respectively. This indicates that some of the nitrates and sulfates were not removed by water regeneration cycles and ultimately led to drop in retention capacity of the carbon.

Since simple water wash was unable to completely regenerate the carbon sample it was studied that if a thermal re-activation can be used for complete regeneration. In this test, spent carbon was placed in a furnace at $950{ }^{\circ} \mathrm{C}$ under inert atmosphere in order to remove any strongly bound contaminants. It was then subjected to ion exchange chromatography as described above. It was found that even after the thermal reactivation at $950{ }^{\circ} \mathrm{C}$ nitrate and sulfate ions were not removed from the carbon surface. This clearly indicates that the drop in retention capacity of the carbon is due to the irreversible adsorption of nitrates and sulfates and such irreversible adsorption must be avoided.

Hence, further work is needed to optimize adsorption/regeneration cycle in order to maintain carbon bed's high retention capacity for SOx/NOx over a long period of time. This includes:

1. Reduce the cycle time to $<7$ hours by increasing feed gas flow or decreasing the amount of carbon. This will reduce the total time of exposure and will limit the adsorption to the surface level.

2. Increase regeneration efficiency by achieving a continuous flow of water through the carbon bed. This will help to remove strongly bound contaminants from the carbon.

3. Eliminate/minimize heating during regeneration step. 


\section{Conclusions}

Activated carbon process for SOx/NOx removal from simulated oxy-coal flue gas was demonstrated. As proposed, the potential advantages of the Task 3 process is the ability to simultaneously remove SOx and NOx impurities, with high efficiency and eliminate or reduce the need for traditional flue gas purification technologies (FGD and SCR). The following major conclusions can be made: 1) Activated carbon material is suitable for simultaneous SOx and NOx removal at elevated pressures and ambient temperatures; 2) Continuity and scalability of the process is achievable through a multi-bed reactor design 3) Good purification performance can be achieved, more specifically the contaminant content in the stream exiting the purification stage is: SOx $<10 \mathrm{ppm}, \mathrm{NOx}<20 \mathrm{ppm}$.

The dual bed system was successfully tested with continuous operation for investigating carbon bed's longevity. The overall SOx and NOx removal efficiencies of $>99.9 \%$ and $>98 \%$, respectively, were achieved. The retention capacity of activated carbon material for SOx and NOx was significantly reduced over a long term test period of 40 days. Optimization of adsorption-regeneration cycle is needed to maintain long term activity of activated carbon material at a higher level and thus minimize the capital cost of the system. Minimization of acidic waste water is also required to reduce disposal costs. 


\section{References}

[1] Mochida I., Korai, Y, Shirahama, M., Kawano S., Hada T., Seo Y., Yoshikawa M., Yasutake, "Removal of SOx and NOx over activated carbon fibers", Carbon vol. $38 \mathrm{p}$ 227-239, 2000.

[2] Santos S., "Impact of Mercury on Oxy-Coal Combustion Technology for Power Generation with $\mathrm{CO}_{2}$ Capture”, IEA Greenhouse Gas R\&D Programme, Stoke Orchard, Cheltenham, UK, 2010.

[3] Tan Y., Mortazavi R., Dureau B., Douglas M.A. “An investigation of mercury distribution and speciation during coal combustion”, Fuel vol. 83 p 2229-2236, 2004.

[4] Chu P., Schmidt C., "Hazardous Air Pollutant Emissions from Coal Fired Power Plants”, Pittsburgh Coal Conference, p 551-556, 1994.

[5] Meij, R. (1994), “Trace element behavior in coal-fired power plants”, Fuel Process. Technol. 39, p 199-217, 1994.

[6] Prestbo, E. M. and Bloom, N. S., "Mercury speciation adsorption MESA method for combustion flue gas: methodology, artifacts, inter-comparison, and atmospheric implications”, Water, Air, Soil Pollut. 80, p 145-158, 1995. 